\title{
An accurate description of the ground and excited states of $\mathrm{SiH}$
}

\author{
Apostolos Kalemos and Aristides Mavridis ${ }^{\text {a) }}$ \\ Laboratory of Physical Chemistry, Department of Chemistry, National and Kapodistrian University \\ of Athens, PO Box 64 004, 15710 Zografou, Athens, Greece \\ Aristophanes Metropoulos \\ Institute of Theoretical and Physical Chemistry, National Hellenic Research Foundation, 48 Vassileos \\ Constantinou Avenue, 11635 Athens, Greece
}

(Received 10 December 2001; accepted 25 January 2002)

\begin{abstract}
The astrophysical importance of the $\mathrm{SiH}$ radical has motivated significant experimental and theoretical work. However, only the $X^{2} \Pi$ and $A^{2} \Delta$ states of SiH have been extensively investigated experimentally, while the study of higher excited states is rather limited. From a theoretical point of view, most of the studies have been focused on spectroscopic and thermochemical quantities of the ground state. The lack of accurate spectroscopic parameters $\left(r_{e}, D_{e}, \omega_{e}, \omega_{e} x_{e}, \alpha_{e}, \bar{D}_{e}, T_{e}\right)$ pertaining to higher excited states was the driving force of the present work, in line with our previous study of the isovalent $\mathrm{CH}$ molecule [A. Kalemos, A. Mavridis, and A. Metropoulos, J. Chem. Phys. 111, 9536 (1999)]. Using the multireference configuration interaction approach coupled with very large correlation-consistent basis sets, we have constructed potential energy curves for 18 molecular states correlating to $\operatorname{Si}\left({ }^{3} P,{ }^{1} D,{ }^{1} S,{ }^{5} S,{ }^{3} P,{ }^{1} P\right)+\mathrm{H}\left({ }^{2} S\right)$. At the same level, the potential energy curve of the ground $\mathrm{SiH}^{+}$state $\left(X^{1} \Sigma^{+}\right)$has also been constructed. We report total energies, dissociation energies, and the usual spectroscopic constants for ${ }^{28} \mathrm{Si}-{ }^{1,2} \mathrm{H}$ and for all states studied. Most of our results are in excellent agreement with existing experimental values. In particular, we believe that our dissociation energy for the $X$ state, $D_{e}=73.28 \mathrm{kcal} / \mathrm{mol}$, is the most reliable reported so far in the literature. (C) 2002 American Institute of Physics.
\end{abstract}

[DOI: $10.1063 / 1.1461817]$

\section{INTRODUCTION}

The $\mathrm{SiH}$ radical was first observed by optical spectroscopy in the 1930's. ${ }^{1-4}$ It is the simplest of the four silicon hydrides and its role in the chemistry of these hydrides as well as in the process of chemical vapor deposition (CVD) of hydrogenated amorphous silicon thin films is well documented. ${ }^{5-34}$ References 31 and 33 list many papers, up to 1991 and 1995, respectively, pertaining to various aspects of silicon hydride chemistry. $\mathrm{SiH}$ is also of astrophysical importance because of its presence in stellar atmospheres and its suspected, but not yet proven, presence in interstellar clouds. ${ }^{35-51}$

$\mathrm{SiH}$ has been studied by optical, infrared, and farinfrared spectroscopy, by radio frequency transitions, and by mass spectroscopy. It is usually produced from the silane $\left(\mathrm{SiH}_{4}\right)$ molecule by flash photolysis, laser-induced photolysis, rf discharge, or by reaction with fluorine atoms. Because of its importance, the assignments of spectral lines and the determination of accurate spectroscopic and thermochemical quantities comprise a large body of experimental ${ }^{52-84}$ and theoretical ${ }^{85-131}$ work on $\mathrm{SiH}$ and SiD.

Only the $X^{2} \Pi$ and the $A^{2} \Delta$ states of $\mathrm{SiH}$ and $\mathrm{SiD}$ have been extensively investigated experimentally. Work on these two states includes the determination of $\Lambda$-doubling transition frequencies for $X^{2} \Pi,{ }^{38,63,65,76}$ radiative lifetimes and oscillator strengths of the $A^{2} \Delta-X^{2} \Pi$ system, ${ }^{43,45,47,61,64,74}$

${ }^{a)}$ Electronic mail: mavridis@chem.uoa.gr various molecular constants, ${ }^{55,56,67,72,78,79,84}$ transition moments, ${ }^{66}$ ionization potentials, ${ }^{55,80,81}$ and dissociation energies and enthalpies of formation. ${ }^{55,59,64,68,80,81,83}$ To our knowledge, only a limited number of experimental papers deal with the higher excited states, but the extracted parameters useful to the present theoretical work are very few, limited mostly to term values. These papers include the work of Verma, ${ }^{55}$ Herzberg et al., ${ }^{60}$ Bollmark et al., ${ }^{62}$ and Johnson and Hudgens. ${ }^{82}$ The latter authors have located a state at $46700 \pm 10 \mathrm{~cm}^{-1}$ and identified it as either a ${ }^{2} \Pi$ or a ${ }^{2} \Sigma^{+}$ state. Based on our present work (vide infra) it is the $F^{2} \Pi$ state. It is noteworthy that there is no experimental value for the dipole moment of $\mathrm{SiH}$ and that the values of its dissociation energy vary significantly. A list of papers on the $\mathrm{SiH}$ and SiD spectroscopy up to 1998 and a brief summary of each work is given by Ram et al. ${ }^{84}$

The first theoretical treatment of $\mathrm{SiH}$ appeared in the literature in 1966 and reported its energy of formation and the excitation energies of the ground- and the low-lying excited states using a semiempirical method. ${ }^{86} \mathrm{Ab}$ initio calculations soon followed, first at the SCF level and then at levels of accuracy beyond SCF. Table I shows results of such calculations relevant to the present work along with the corresponding latest experimental values. Often, work on $\mathrm{SiH}$ was part of a larger investigation on silicon hydrides. Oikawa et al. ${ }^{109}$ investigated the mechanism of formation of $\mathrm{SiH}$ during plasma CVD. Allen and Schaefer ${ }^{111}$ did an extensive investigation of the ground-state properties of the silicon hydrides and gave extensive references to related experimental 
TABLE I. Previous theoretical estimates of total energies $E$ (hartree), dissociation energies $D_{e}(\mathrm{kcal} / \mathrm{mol})$, bond distances $r_{e}(\AA)$, harmonic frequencies $\omega_{e}\left(\mathrm{~cm}^{-1}\right)$, anharmonic corrections $\omega_{e} x_{e}\left(\mathrm{~cm}^{-1}\right)$, rotational-vibrational coupling constants $\alpha_{e}\left(\mathrm{~cm}^{-1}\right)$, centrifugal distortions $\bar{D}_{e}\left(\mathrm{~cm}^{-1}\right)$, dipole moments $\mu(\mathrm{D})$, and energy separations $T_{e}(\mathrm{kcal} / \mathrm{mol})$ along with recent experimental values of the $\mathrm{SiH}$ molecule and in different states.

\begin{tabular}{|c|c|c|c|c|c|c|c|c|c|}
\hline$-E$ & $D_{e}$ & $r_{e}$ & $\omega_{e}$ & $\omega_{e} x_{e}$ & $\alpha_{e}$ & $\bar{D}_{e}\left(10^{4}\right)$ & $\mu$ & $T_{e}$ & Ref./year \\
\hline \multicolumn{10}{|l|}{$\left(X^{2} \Pi\right)$} \\
\hline & 76.33 & & & & & & & & $86 / 1966^{\mathrm{a}}$ \\
\hline 289.4362 & 51.43 & 1.521 & & & & & & & $87 / 1967^{b}$ \\
\hline 289.3234 & & 1.561 & 2200 & & & & & & $90 / 1971^{\mathrm{c}}$ \\
\hline 289.540770 & 71.26 & 1.526 & 2034.7 & 36.0 & 0.216 & & 0.141 & & $96 / 1975^{\mathrm{d}}$ \\
\hline 289.50520 & 65.72 & 1.552 & 1965.9 & 37.2 & 0.2151 & 3.9 & & & $104 / 1982^{\mathrm{e}}$ \\
\hline 289.5180 & 70.11 & 1.544 & 2015 & 39.0 & 0.208 & & 0.124 & & $105 \mathrm{a} / 1983^{\mathrm{f}}$ \\
\hline \multirow[t]{4}{*}{289.51387} & 72.60 & 1.51521 & 1949 & & & & & & $107 / 1985^{\mathrm{g}}$ \\
\hline & 65.93 & & 2181.24 & & & & & & $108 / 1985^{\mathrm{h}}$ \\
\hline & & 1.520 & 2044 & & & & 0.160 & & $110 / 1986^{\mathrm{i}}$ \\
\hline & & 1.523 & 2022 & & & & 0.118 & & $110 / 1986^{\mathrm{j}}$ \\
\hline 289.528786 & & 1.52142 & 2062 & 38.5 & 0.21755 & & 0.077 & & $111 / 1986^{\mathrm{k}}$ \\
\hline 289.541256 & 72.09 & 1.520 & 2057.8 & 37.8 & 0.218 & & 0.123 & & $113 / 1987^{1}$ \\
\hline \multirow[t]{2}{*}{289.53359} & & 1.541 & 1996.4 & 28.94 & & & 0.080 & & $114 / 1987^{\mathrm{m}}$ \\
\hline & & 1.5201 & & & & & 0.1218 & & $122 / 1992^{\mathrm{n}}$ \\
\hline 289.554544 & 73.20 & 1.52142 & & & & & & & $123 / 1992^{\circ}$ \\
\hline 289.54630 & 70.61 & 1.5259 & & & & & & & $124 / 1993^{p}$ \\
\hline 289.52903 & & 1.5108 & & & & & & & $125 \mathrm{a} / 1993^{\mathrm{q}}$ \\
\hline \multirow[t]{2}{*}{289.55225} & 72.90 & 1.5236 & 2036.2 & 35.8 & 0.2147 & & & & $126 / 1993^{\mathrm{r}}$ \\
\hline & & 1.533 & 2050 & & & & & & $127 / 1994^{\mathrm{s}}$ \\
\hline 289.524369 & & 1.5201 & & & & & 0.091 & & $128 / 1996^{\mathrm{t}}$ \\
\hline \multirow[t]{4}{*}{289.5568} & 73.61 & 1.521 & & & & & & & $131 / 1999^{u}$ \\
\hline & & 1.503 & & & & & 0.140 & & $132 / 1999^{\mathrm{v}}$ \\
\hline & $D_{o}^{o} \leqslant 70.57$ & $1.5201_{0}$ & 2041.80 & 35.51 & 0.2190 & 3.97 & & & $67 / 1979^{w}$ \\
\hline & $72.35-73.46$ & $1.51966(7)$ & $2042.5229(8)$ & $36.0552(5)$ & $0.21814(2)$ & $4.0556(45)$ & & & $78 / 1986^{\mathrm{x}}$ \\
\hline \multicolumn{10}{|l|}{$\left(a^{4} \Sigma^{-}\right)$} \\
\hline & & & & & & & & 61.57 & $86 / 1966^{\mathrm{a}}$ \\
\hline 289.2857 & & 1.522 & 2255 & & & & & 23.98 & $90 / 1971^{c}$ \\
\hline \multirow[t]{3}{*}{289.44768} & 29.70 & 1.522 & 1982.5 & 60.6 & 0.2858 & 4.3 & & 36.09 & $104 / 1982^{\mathrm{e}}$ \\
\hline & 33.90 & 1.511 & 2030 & 65.0 & 0.313 & & 0.030 & 36.44 & $105 \mathrm{a} / 1983^{\mathrm{f}}$ \\
\hline & & 1.5201 & & & & & 0.1383 & & $122 / 1992^{\mathrm{n}}$ \\
\hline \multirow[t]{3}{*}{289.47280} & & 1.5108 & & & & & & 35.28 & $125 \mathrm{a} / 1993^{\mathrm{q}}$ \\
\hline & & 1.501 & 2086 & & & & & 38.97 & $127 / 1994^{\mathrm{s}}$ \\
\hline \multirow{2}{*}{\multicolumn{10}{|c|}{$\left(A^{2} \Delta\right)$}} \\
\hline & & & & & & & & & \\
\hline \multirow[t]{2}{*}{289.2096} & & 1.554 & 1955 & & & & & 71.49 & $90 / 1971^{c}$ \\
\hline & 20.06 & 1.546 & 1797 & 91.0 & 0.420 & & 0.118 & 71.26 & $105 \mathrm{a} / 1983^{\mathrm{f}}$ \\
\hline \multirow[t]{2}{*}{289.426924} & & 1.517 & 1884.4 & 68.4 & 0.242 & & & 71.72 & $113 / 1987^{1}$ \\
\hline & & 1.5201 & & & & & 0.1451 & & $122 / 1992^{\mathrm{n}}$ \\
\hline 289.41511 & & 1.5108 & & & & & & 71.49 & $125 \mathrm{a} / 1993^{\mathrm{q}}$ \\
\hline & & $1.5234_{7}$ & 1858.90 & $99.17_{5}$ & 0.3445 & 5.24 & & 69.48 & $67 / 1979^{w}$ \\
\hline & $20.58-21.69$ & $1.5197816(21)$ & & & $0.215119(15)$ & & & 69.35 & $84 / 1998^{z}$ \\
\hline$\left(B^{2} \Sigma^{-}\right)$ & & & & & & & & & \\
\hline & & & & & & & & 70.71 & $86 / 1966^{\mathrm{a}}$ \\
\hline 289.2011 & & & & & & & & 76.75 & $90 / 1971^{c}$ \\
\hline & & & & & & & & 75.64 & $105 \mathrm{a} / 1983^{\mathrm{f}}$ \\
\hline 289.40849 & & 1.5108 & & & & & & 75.64 & $125 \mathrm{a} / 1993^{q}$ \\
\hline & & & & & & & & $73.31-76.24$ & $53 / 1960^{\text {aa }}$ \\
\hline$\left(C^{2} \Sigma^{+}\right)$ & & & & & & & & & \\
\hline & & & & & & & & 100.78 & $86 / 1966^{\mathrm{a}}$ \\
\hline 289.1780 & & 1.585 & 1710 & & & & & 91.09 & $90 / 1971^{\mathrm{c}}$ \\
\hline & & 1.553 & $1550 \pm 50$ & & & & 0.171 & 89.71 & $105 \mathrm{a} / 1983^{\mathrm{f}}$ \\
\hline & & 1.5201 & & & & & 0.1141 & & $122 / 1992^{\mathrm{n}}$ \\
\hline 289.38314 & & 1.5108 & & & & & & 91.55 & $125 \mathrm{a} / 1993^{\mathrm{q}}$ \\
\hline 1 st min & & $3.8_{5}$ & & & & & & 91.01 & $67 / 1979^{w}$ \\
\hline 2nd min & & $1.61_{8}$ & & & & & & 91.04 & $67 / 1979^{w}$ \\
\hline$\left(D^{2} \Sigma^{+}\right)$ & & & & & & & & 104.70 & $105 \mathrm{a} / 1983^{\mathrm{f}}$ \\
\hline$\left(E^{2} \Sigma^{+}\right)$ & & & & & & & & 114.61 & $105 \mathrm{a} / 1983^{\mathrm{f}}$ \\
\hline$\left(c^{4} \Sigma^{-}\right)$ & & & & & & & & & \\
\hline & & 1.970 & 1245 & 22.0 & 0.094 & & & 150.13 & $105 a / 1983^{f}$ \\
\hline & & & & & & & & 131.5 & $66 / 1979^{y}$ \\
\hline$\left(F^{2} \Pi\right)$ & & & & & & & & & \\
\hline 289.0489 & & 1.571 & 1944 & & & & & 172.27 & $90 / 1971^{\mathrm{c}}$ \\
\hline & & & & & & & & 132.14 & $105 \mathrm{a} / 1983^{\mathrm{f}}$ \\
\hline & & & & & & & & 133.52 & $82 / 1989^{\text {bb }}$ \\
\hline
\end{tabular}


TABLE I. (Continued.)

\begin{tabular}{|c|c|c|c|c|c|c|c|c|c|}
\hline$-E$ & $D_{e}$ & $r_{e}$ & $\omega_{e}$ & $\omega_{e} x_{e}$ & $\alpha_{e}$ & $\bar{D}_{e}\left(10^{4}\right)$ & $\mu$ & $T_{e}$ & Ref./year \\
\hline$\left(G^{2} \Sigma^{+}\right)$ & & & & & & & & 130.06 & $105 \mathrm{a} / 1983^{f}$ \\
\hline$\left(H^{2} \Delta\right)$ & & & & & & & & 139.52 & $105 \mathrm{a} / 1983^{\mathrm{f}}$ \\
\hline & & $1.48_{1}$ & & & & & & 141.59 & $67 / 1979^{w}$ \\
\hline$\left(I^{2} \Pi\right)$ & & 1.01 & & & & & & 140.44 & $105 \mathrm{a} / 1983^{\mathrm{f}}$ \\
\hline$\left(J^{2} \Pi\right)$ & & & & & & & & $\sim 148.74^{\mathrm{cc}}$ & $105 \mathrm{a} / 1983^{f}$ \\
\hline$\left({ }^{2} \Sigma^{+}\right)$ & & & & & & & & 149.44 & $105 \mathrm{a} / 1983^{f}$ \\
\hline & & $1.517_{2}$ & & & & 3.92 & & 152.66 & $67 / 1979^{w}$ \\
\hline$\left(e^{4} \Pi\right)$ & & & & & & & & 163.73 & $105 \mathrm{a} / 1983^{\mathrm{f}}$ \\
\hline
\end{tabular}

a Semiempirical calculations at $r=1.48 \AA$.

${ }^{b}$ SCF with a large basis set of STFs $(6 s 5 p 1 d / 3 s 1 p)$, and extensive optimization of the orbital exponents; the total energy reported has been calculated at the experimental $r_{e}$. An "experimental" energy value of -290.549 hartree is also reported.

${ }^{\mathrm{c}} \mathrm{SCF} / \mathrm{CISD}[6 s 3 \mathrm{p} / 1 \mathrm{~s}]$ basis; reported energies and $T_{e}$ 's at $r=2.87 \mathrm{bohr}$.

${ }^{\mathrm{d}}$ CEPA $\left[13 s 10 p 2 d 1 f / 6 s 2 p 1 d_{\sigma}\right]$ basis set; the reported $r_{e}$ value is estimated to be reduced by $0.004 \AA$ when core-valence correlation effects are taken into account.

${ }^{\mathrm{e}} \mathrm{MCSCF}+1+2,[4 s 3 p 1 d / 3 s 1 p]$ basis set.

${ }^{\mathrm{f}}$ Full-CI estimate of the MRD-CI results using two different basis sets, [ $\left.7 s 5 p 4 d 1 f / 3 s 1 p 1 d\right]$, and [ $\left.7 s 5 p 2 d 1 f / 3 s 1 p 1 d\right]$ for the description of Rydberg and valence states, respectively. $T_{e}$ 's are vertical excitations from the ground state at the equilibrium geometry of the $a^{4} \Sigma^{-}$state; dipole moments are also calculated at this internuclear separation.

${ }^{\mathrm{g}} \mathrm{MP} 4 / 6-31+\mathrm{G}(2 d f, p) / / \mathrm{HF} / 6-31 \mathrm{G}(d)$ results; the $r_{e}$ was not optimized to five significant figures but is given to this precision for reasons of reproducibility. ${ }^{\mathrm{h}} \mathrm{MP} 4 / 6-31 \mathrm{G}^{* *} / / \mathrm{HF} / 6-31 \mathrm{G}^{*}$ results, coupled with empirical correction factors to account for systematic deficiencies due to basis set truncation.

${ }^{i} \mathrm{SCF}+1+2$ (=CISD) using large STO basis sets $(8 s 6 p 3 d 2 f / 4 s 3 p 2 d)$.

${ }^{\mathrm{j}}$ Coupled pair functional (CPF) calculations, basis set the same as in $\mathrm{i}$.

${ }^{\mathrm{k}} \mathrm{CISD} /[6 s 5 p 2 d / 4 s 2 p]$.

${ }^{\mathrm{l}} \mathrm{CASSCF}+$ contracted CI/[ $\left.8 s 6 p 4 d 2 f / 7 s 4 p 1 d\right]$.

${ }^{\mathrm{m} C I} 4$ (SDQ)/[6s5p2d/4s $\left.2 p\right]$.

${ }^{\mathrm{n}}$ Valence-shell Hamiltonian method based on quasidegenerate MBPT; [ $7 s 5 p 2 d / 3 s 1 p 1 d$ ] basis set. All calculations at the $r_{e}$ of the $X$-state.

${ }^{\circ} \mathrm{CCSD}(\mathrm{T}) /[6 s 5 p 3 d 2 f 1 g / 4 s 3 p 2 d 1 f] / / \mathrm{CISD} /[6 s 5 p 2 d / 4 s 2 p]$.

${ }^{\mathrm{P}} \mathrm{G} 1 / / \mathrm{MP} 2 / 6-31 \mathrm{G}(d)$.

${ }^{\mathrm{q}} \mathrm{MRCI} / \mathrm{TZP}$; reported $T_{e}$ 's are vertical excitation energies calculated at $r=2.855$ bohr.

${ }^{\mathrm{r}} \mathrm{CASSCF}+1+2 / \mathrm{cc}-\mathrm{pV} 5 \mathrm{Z}$.

${ }^{\mathrm{s}} \mathrm{MRCI}+\mathrm{Q} / / \mathrm{MCSF}$ results using pseudopotential on $\mathrm{Si}$

${ }^{\mathrm{t}} \mathrm{CISDT}^{+} / \mathrm{POL} 1 ;[7 s 5 p 2 d / 3 s 2 p]$ basis at the experimental $r_{e}=1.5201 \AA$ from Ref. 67

${ }^{u} U G A-C C S D(T) / a u g-c c-p V 6 Z$ results for the total energy and $r_{e}$, while the $D_{e}$ value takes into account the CBS limit. Corrections for core-valence correlation effects, scalar relativistic, and spin-orbit effects give a $D_{e}$ value of $73.3 \mathrm{kcal} / \mathrm{mol}$.

${ }^{\mathrm{v}}$ Multi-reference CC approach/[7s5p2d/3s $\left.2 p\right]$.

${ }^{\mathrm{w}}$ Experimental results.

${ }^{\mathrm{x}}$ Experimental results from analysis of the infrared emission spectrum of the ${ }^{28} \mathrm{SiH}$ radical; $D_{e}$ value from Ref. 113 .

${ }^{\mathrm{y}}$ Shock-tube determination of absorption cross sections.

${ }^{\mathrm{z}}$ Fourier transform emission spectroscopy on the $A^{2} \Delta \leftarrow X^{2} \Pi$ transitions of SiH; $T_{e}\left(=24257.127(1) \mathrm{cm}^{-1}\right)$ from Ref. 65 .

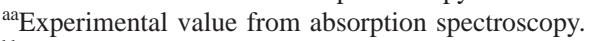

${ }^{b b}$ Experimental value from resonance-enhanced multiphoton ionization spectroscopy.

${ }^{c c}$ Approximately obtained from Fig. 4 of Ref. 105a.

and theoretical work. Kalcher ${ }^{114}$ did extensive comparisons between $a b$ initio and pseudopotential calculations at various levels of accuracy for the neutral and anionic species of $\mathrm{SiH}_{n}$ $(n=1,2,3)$, trying to judge the validity of pseudopotentials for calculations on larger silicon hydride clusters. Greeff and Lester ${ }^{129}$ have done a Monte Carlo (MC) calculation on $\mathrm{SiH}$ as a means of estimating the advisability of $\mathrm{MC}$ calculations on larger silicon hydride molecules where huge basis sets would be required for accuracy comparable to MC. Other papers deal exclusively with the ground- and the low-lying excited states of $\mathrm{SiH}$. Meyer and Rosmus ${ }^{96,98}$ used large basis sets with the pseudonatural orbitals-configuration interaction (PNO-CI) and coupled electron pair approximation (CEPA) methods to calculate energies, ionization potentials, and spectroscopic constants of the ground state. Richards and co-workers ${ }^{97,102,103}$ calculated the $\Lambda$-doubling in the lowest rotational level of the $X^{2} \Pi$. Mavridis and Harrison ${ }^{104}$ have done $a b$ initio calculations on the $X^{2} \Pi$ and $a^{4} \Sigma^{-}$states. Petterson and Langhoff ${ }^{110}$ calculated dipole moments of the
TABLE II. Total energies $E$ (hartree) of the ${ }^{3} P\left(3 s^{2} 3 p^{2}\right),{ }^{1} D\left(3 s^{2} 3 p^{2}\right)$, ${ }^{1} S\left(3 s^{2} 3 p^{2}\right),{ }^{5} S\left(3 s^{1} 3 p^{3}\right),{ }^{3} P\left(3 s^{2} 3 p^{1} 4 s^{1}\right),{ }^{1} P\left(3 s^{2} 3 p^{1} 4 s^{1}\right),{ }^{3} D\left(3 s^{1} 3 p^{3}\right)$, and ${ }^{3} D\left(3 s^{2} 3 p^{1} 4 p^{1}\right)$ Si states and corresponding energy gaps $\Delta E(\mathrm{eV})$ with respect to the ground state at the MRCI level of theory. Experimental values in parentheses.

\begin{tabular}{ccc}
\hline \hline \multicolumn{1}{c}{ State } & $-E^{\mathrm{b}}$ & $\Delta E^{\mathrm{c}}$ \\
\hline${ }^{3} P\left(3 s^{2} 3 p^{2}\right)^{\mathrm{a}}$ & 288.940143 & $0.0(0.0)$ \\
${ }^{1} D\left(3 s^{2} 3 p^{2}\right)$ & 288.911836 & $0.770(0.762)$ \\
${ }^{1} S\left(3 s^{2} 3 p^{2}\right)$ & 288.870350 & $1.899(1.890)$ \\
${ }^{5} S\left(3 s^{1} 3 p^{3}\right)$ & 288.795048 & $3.948(4.113)$ \\
${ }^{3} P\left(3 s^{2} 3 p^{1} 4 s^{1}\right)$ & 288.757063 & $4.982(4.923)$ \\
${ }^{1} P\left(3 s^{2} 3 p^{1} 4 s^{1}\right)$ & 288.751215 & $5.141(5.064)$ \\
${ }^{3} D\left(3 s^{1} 3 p^{3}\right)$ & 288.735503 & $5.569(5.598)$ \\
${ }^{3} D\left(3 s^{2} 3 p^{1} 4 p^{1}\right)$ & 288.720387 & $5.980(5.953)$ \\
\hline \hline
\end{tabular}

${ }^{a}$ The SCF energy of the ${ }^{3} P$ state is $-288.854346 h$ as compared to the numerical HF value of $-288.8543624 h$, Ref. 138.

${ }^{\mathrm{b}}$ The active space of the CASSCF wave functions includes 13 orbitals related to the $3 s, 3 p, 3 d, 4 s$, and $4 p$ atomic orbitals. Spherical symmetry was induced by performing state-average CASSCF calculations.

${ }^{\mathrm{c}}$ Experimental values, averaged over $M_{J}$, are taken from the Atomic Spectra Database of NIST, Ref. 140. 1 hartree $=27.2114 \mathrm{eV}$. 
TABLE III. Total energies $E$ (hartree), dissociation energies $D_{e}(\mathrm{kcal} / \mathrm{mol})$, bond distances $r_{e}(\AA)$, dipole moments $\mu(\mathrm{D})$, and energy separations $T_{e}(\mathrm{kcal} / \mathrm{mol})$ of all bound calculated states of the $\mathrm{SiH}$ system. Existing experimental results are also included.

\begin{tabular}{|c|c|c|c|c|c|c|}
\hline State & Method $^{\mathrm{a}}$ & $-E$ & $D_{e}$ & $r_{e}$ & $\mu$ & $T_{e}$ \\
\hline \multirow[t]{6}{*}{$X^{2} \Pi$} & SCF & 289.437788 & 52.25 & 1.5127 & 0.269 & 0.0 \\
\hline & CASSCF & 289.533299 & 65.63 & 1.5196 & 0.150 & 0.0 \\
\hline & MRCI & 289.557373 & 73.55 & 1.5223 & 0.124 & 0.0 \\
\hline & $\mathrm{MRCI}+\mathrm{Q}$ & 289.5577 & 73.73 & 1.5227 & & 0.0 \\
\hline & $\operatorname{CCSD}(\mathrm{T})$ & 289.556482 & 73.57 & 1.5221 & & 0.0 \\
\hline & Expt. & & $72.35-73.46^{\mathrm{b}}$ & $1.51966_{7}^{\mathrm{c}}$ & & 0.0 \\
\hline \multirow[t]{6}{*}{$a^{4} \Sigma^{-}$} & SCF & 289.406304 & 32.49 & 1.4653 & -0.144 & 19.76 \\
\hline & CASSCF & 289.476683 & 29.69 & 1.5006 & -0.022 & 35.53 \\
\hline & MRCI & 289.495594 & 34.73 & 1.4974 & -0.027 & 38.77 \\
\hline & $\mathrm{MRCI}+\mathrm{Q}$ & 289.4957 & 34.79 & 1.4974 & & 38.90 \\
\hline & $\operatorname{CCSD}(\mathrm{T})$ & 289.494509 & 34.68 & 1.4953 & & 38.89 \\
\hline & Expt. $^{\mathrm{d}}$ & & & & & 14.30 \\
\hline \multirow{4}{*}{$A^{2} \Delta$} & CASSCF & 289.418798 & 15.86 & 1.5351 & 0.110 & 71.85 \\
\hline & MRCI & 289.447424 & 22.28 & 1.5240 & 0.098 & 68.99 \\
\hline & $\mathrm{MRCI}+\mathrm{Q}$ & 289.4479 & 22.45 & 1.5237 & & 68.91 \\
\hline & Expt. & & $20.58-21.69^{\mathrm{e}}$ & $1.5197816_{21}{ }^{\mathrm{f}}$ & & $69.35^{\mathrm{g}}$ \\
\hline \multirow[t]{6}{*}{$B^{2} \Sigma^{-}$} & MRCI & 289.440547 & 0.19 & 3.440 & 0.093 & 73.31 \\
\hline & $\mathrm{MRCI}+\mathrm{Q}$ & 289.4406 & 0.20 & 3.426 & & 73.49 \\
\hline & Expt. $^{\mathrm{b}}$ & & & & & $73.31-76.24$ \\
\hline & & & Local minimum & & & \\
\hline & MRCI & 289.439778 & & 1.7154 & 0.621 & \\
\hline & $\mathrm{MRCI}+\mathrm{Q}$ & 289.4400 & & 1.7128 & & \\
\hline \multirow[t]{6}{*}{$C^{2} \Sigma^{+}$} & MRCI & 289.416551 & 2.89 & 1.5338 & 0.178 & 88.37 \\
\hline & $\mathrm{MRCI}+\mathrm{Q}$ & 289.4171 & 3.17 & 1.5328 & & 88.26 \\
\hline & Expt. $^{i}$ & & Local minimum & & & \\
\hline & MRCI & 289.414926 & & 2.40 & -1.245 & \\
\hline & $\mathrm{MRCI}+\mathrm{Q}$ & 289.4153 & & 2.38 & & \\
\hline & Expt. $^{\mathrm{i}}$ & & & & & \\
\hline \multirow[t]{2}{*}{$D^{2} \Sigma^{+}$} & MRCI & 289.402681 & 20.29 & 1.7923 & -0.279 & 97.07 \\
\hline & $\mathrm{MRCI}+\mathrm{Q}$ & 289.4036 & 20.94 & 1.7943 & & 96.73 \\
\hline \multirow[t]{5}{*}{$E^{2} \Sigma^{+}$} & MRCI & 289.374571 & 73.67 & 1.5374 & -0.975 & 114.71 \\
\hline & $\mathrm{MRCI}+\mathrm{Q}$ & 289.3757 & 74.30 & 1.5346 & & 114.22 \\
\hline & & & Local minimum & & & \\
\hline & MRCI & 289.303480 & & 3.1824 & -9.552 & \\
\hline & $\mathrm{MRCI}+\mathrm{Q}$ & 289.3049 & & 3.1949 & & \\
\hline \multirow[t]{4}{*}{$c^{4} \Sigma^{-}$} & CASSCF & 289.325673 & 22.60 & 1.9802 & -0.031 & 130.29 \\
\hline & MRCI & 289.343814 & 30.60 & 1.9453 & 0.049 & 134.01 \\
\hline & $\mathrm{MRCI}+\mathrm{Q}$ & 289.3441 & 30.74 & 1.9428 & & 134.08 \\
\hline & Expt. $^{d}$ & & & & & 131.5 \\
\hline \multirow[t]{3}{*}{$F^{2} \Pi$} & MRCI & $\sim 289.3412$ & & $\sim 1.43$ & -0.363 & $\sim 135$ \\
\hline & $\mathrm{MRCI}+\mathrm{Q}$ & $\sim 289.342$ & & $\sim 1.43$ & & \\
\hline & Expt. $^{j}$ & & & & & 133.52 \\
\hline \multirow[t]{2}{*}{$G^{2} \Sigma^{+}$} & MRCI & 289.279506 & 17.66 & 2.5387 & -2.009 & \\
\hline & $\mathrm{MRCI}+\mathrm{Q}$ & 289.2809 & 18.38 & 2.5340 & & \\
\hline \multirow[t]{3}{*}{$H^{2} \Delta$} & MRCI & $\sim 289.3228$ & $\sim 54.8$ & $\sim 1.56$ & 0.331 & $\sim 147.2$ \\
\hline & $\mathrm{MRCI}+\mathrm{Q}$ & $\sim 289.382$ & $\sim 81.6$ & $\sim 1.56$ & & $\sim 110$ \\
\hline & Expt. $^{\mathrm{k}}$ & & & & & 141.59 \\
\hline \multirow[t]{2}{*}{$I^{2} \Pi$} & MRCI & 289.310652 & 33.63 & 3.175 & -9.543 & 154.82 \\
\hline & $\mathrm{MRCI}+\mathrm{Q}$ & 289.3116 & 34.15 & 3.17 & & 154.43 \\
\hline \multirow[t]{3}{*}{$e^{4} \Pi$} & CASSCF & 289.277442 & 19.67 & 1.5157 & -2.301 & 160.55 \\
\hline & MRCI & 289.300964 & 27.53 & 1.5081 & -2.316 & 160.90 \\
\hline & $\mathrm{MRCI}+\mathrm{Q}$ & 289.3013 & 27.68 & 1.5082 & & 160.9 \\
\hline \multirow[t]{2}{*}{$f^{4} \Delta$} & MRCI & 289.263953 & 17.86 & 1.5497 & -2.149 & 181.12 \\
\hline & $\mathrm{MRCI}+\mathrm{Q}$ & 289.2646 & 7.86 & 1.5545 & & 183.9 \\
\hline$J^{2} \Pi$ & MRCI & $\sim 289.2577$ & $\sim 4.06$ & $\sim 2.33$ & & $\sim 188$ \\
\hline \multirow[t]{2}{*}{$g^{4} \Sigma^{+}$} & MRCI & 289.259725 & 1.60 & 1.5483 & -1.847 & 186.78 \\
\hline & $\mathrm{MRCI}+\mathrm{Q}$ & 289.2602 & 1.78 & 1.551 & & 186.7 \\
\hline
\end{tabular}

${ }^{a}+Q$, refers to the multireference Davidson correction.

${ }^{\mathrm{b}}$ Reference 113.

${ }^{\mathrm{c}}$ Reference 84.

${ }^{\mathrm{d}}$ Reference 66.

${ }^{\mathrm{e}}$ Reference 113; see also the text.

${ }^{\mathrm{f}}$ Reference 84.

${ }^{\mathrm{g}}$ Reference 65.

${ }^{\mathrm{h}}$ Reference 53.

${ }^{\text {iS }}$ See the text.

${ }^{\mathrm{j}}$ Reference 82.

${ }^{\mathrm{k}}$ Reference 67. 
TABLE IV. Harmonic frequencies $\omega_{e}$, anharmonicites $\omega_{e} x_{e}$, rotational vibrational couplings $\alpha_{e}$, and centrifugal distortions $\bar{D}_{e}$ in $\mathrm{cm}^{-1}$ of the ${ }^{28} \mathrm{Si}-{ }^{1,2} \mathrm{H}$ system in different states at the MRCI level.

\begin{tabular}{|c|c|c|c|c|}
\hline State & $\omega_{e}$ & $\omega_{e} x_{e}$ & $\alpha_{e}$ & $\bar{D}_{e} \times 10^{4}$ \\
\hline \multicolumn{5}{|c|}{${ }^{28} \mathrm{Si}-{ }^{1} \mathrm{H}$} \\
\hline$X^{2} \Pi$ & 2043.15 & 35.09 & 0.213 & 4.01 \\
\hline Expt. $^{\mathrm{a}}$ & 2042.52 & 36.06 & 0.218 & 4.06 \\
\hline$a^{4} \Sigma^{-}$ & 2059.16 & 61.07 & 0.287 & 4.44 \\
\hline$A^{2} \Delta$ & 1853.15 & 78.39 & 0.375 & 5.39 \\
\hline Expt. $^{b}$ & 1858.90 & 99.17 & 0.344 & 5.24 \\
\hline$B^{2} \Sigma_{g}^{-c}$ & 81.74 & & & \\
\hline$C^{2} \Sigma_{g}^{g} \mathrm{c}$ & 285.12 & & & \\
\hline$D^{2} \Sigma^{8}+$ & 2147.31 & 402.51 & & \\
\hline$E^{2} \Sigma_{l}^{+c}$ & 647.85 & 20.40 & 0.021 & 0.506 \\
\hline$E^{2} \Sigma_{g}^{+c}$ & 2410.86 & 70.76 & 0.257 & 2.59 \\
\hline$c^{4} \Sigma^{8}-$ & 1253.63 & 15.60 & 0.042 & 2.47 \\
\hline$I^{2} \Pi$ & 599.33 & -0.815 & -0.007 & 0.48 \\
\hline$e^{4} \Pi$ & 1925.53 & 61.61 & 0.349 & 4.89 \\
\hline$f^{4} \Delta$ & 1661.86 & 65.66 & 0.319 & 4.37 \\
\hline$g^{4} \Sigma^{+}$ & 1639.63 & $\begin{array}{c}32.94 \\
{ }^{28} \mathrm{Si}-{ }^{2} \mathrm{H}\end{array}$ & 0.217 & 3.92 \\
\hline$X^{2} \Pi$ & 1470.75 & 18.54 & 0.080 & 1.07 \\
\hline Expt. $^{b}$ & 1469.32 & 18.23 & 0.078 & 1.054 \\
\hline$a^{4} \Sigma^{-}$ & 1480.17 & 30.65 & 0.107 & 1.17 \\
\hline$A^{2} \Delta$ & 1333.66 & 40.79 & 0.137 & 1.33 \\
\hline Expt. $^{\mathrm{b}}$ & 1328.08 & 48.11 & 0.132 & 1.379 \\
\hline$B^{2} \Sigma_{g}^{-c}$ & 60.59 & & & \\
\hline$C^{2} \Sigma_{g}^{0} \mathrm{c}$ & 229.71 & & & \\
\hline$D^{2} \Sigma^{8}+$ & 1570.38 & 253.34 & & \\
\hline$E^{2} \Sigma_{l}^{+c}$ & 456.33 & 3.18 & 0.011 & 0.125 \\
\hline$E^{2} \Sigma_{g}^{+c}$ & 1725.99 & 27.66 & 0.101 & 0.699 \\
\hline$c^{4} \Sigma^{8}-$ & 902.85 & 9.09 & 0.015 & 0.66 \\
\hline$I^{2} \Pi$ & 435.33 & 2.15 & 0.002 & 0.14 \\
\hline$e^{4} \Pi$ & 1384.93 & 31.79 & 0.123 & 1.29 \\
\hline$f^{4} \Delta$ & 1210.50 & 44.81 & 0.154 & 1.42 \\
\hline$g^{4} \Sigma^{+}$ & 1219.23 & 45.62 & 0.153 & 1.39 \\
\hline
\end{tabular}

${ }^{\mathrm{a}}$ Reference 78.

${ }^{\mathrm{b}}$ Reference 67.

c"g" and " $l$ " refer to global and local minima; see the text.

$X^{2} \Pi$ state using a large Slater-type orbitals (STO) basis set with a singlereference CISD. Larsson ${ }^{113}$ used a complete active space self-consistent field (CASSCF)-contracted CI method and calculated the potential curves of the $X^{2} \Pi$ and $A^{2} \Delta$ states, transition moments, and dipole moments as functions of internuclear separation, as well as useful spectroscopic parameters. Winter and Millie ${ }^{125}$ explained in terms of hybridization the differences in the $X^{2} \Pi-a^{4} \Sigma^{-}$gaps between the states of $\mathrm{SiH}$ and $\mathrm{CH}$. Calculations on higher excited states of $\mathrm{SiH}$ were first done by Wirsam, ${ }^{90}$ who studied six states by a low-accuracy calculation employing a limited $\mathrm{CI}$ and a double-zeta basis but without polarization functions. Lewerenz et al., ${ }^{105}$ were the first to do extensive calculations on $\mathrm{SiH}$ at an acceptable accuracy including many excited states. They used DZP-type basis sets with the multireference double configuration interaction (MRDCI) package and a selection threshold resulting in about 10000 spinadapted functions. They computed the potential energy curves for all valence- and many Rydberg states, as well as dipole moments, electronic transition moments, spin-orbit coupling parameters, and other spectroscopic and thermochemical properties. They also did a charge distribution analysis. Other workers have computed, at various degrees of

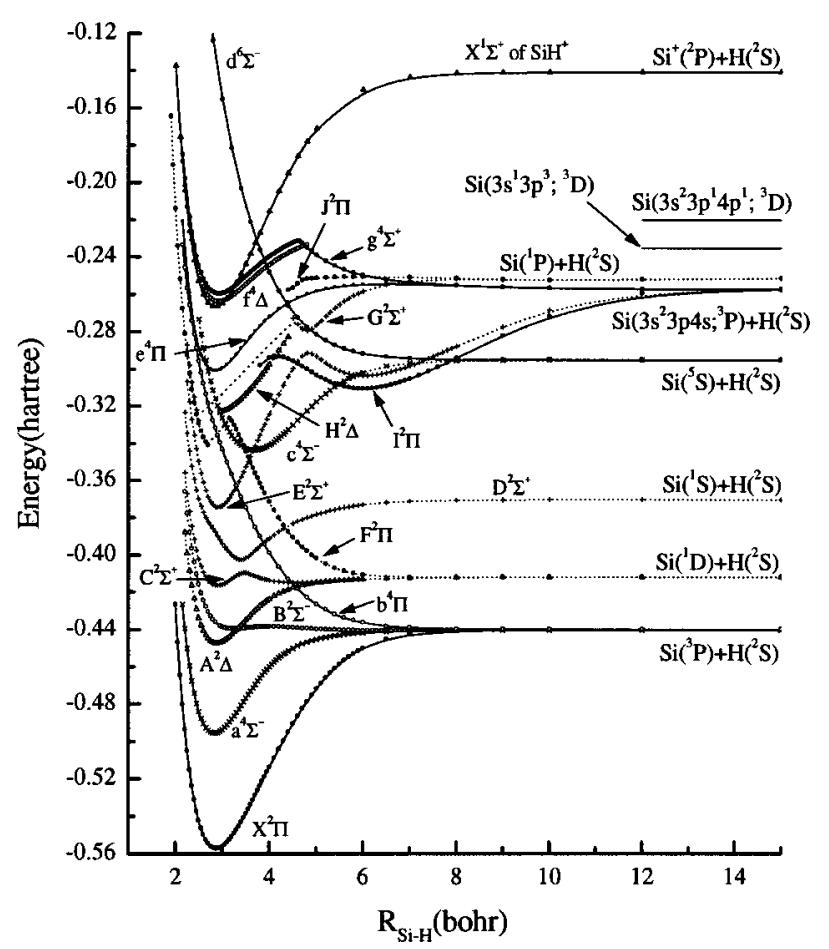

FIG. 1. Potential energy curves of all calculated states of $\mathrm{SiH}$ and the $X^{1} \Sigma^{+}$ state of $\mathrm{SiH}^{+}$at the MRCI level of theory. All energies have been shifted by +289.00 hartree.

accuracy, values for the ionization energy, ${ }^{87,90,98,115,123}$ the electron affinity, ${ }^{88,105,114,124}$ the transition probabilities and $f$-factors $\left(A^{2} \Delta \leftarrow X^{2} \Pi\right),{ }^{92,100,113}$ the $\Lambda$-doubling, ${ }^{97,102,103}$ the spin-orbit constant (for $X^{2} \Pi$ ), ${ }^{102,119}$ and the enthalpy of formation. ${ }^{107,108,116-118,120,121,123,124}$ Notice that not all states have been identified in the literature and there is a confusion regarding their labeling.

The aim of the present work is to construct with the highest accuracy presently possible the potential energy curves (PEC) for all molecular states arising from the lowest six states of Si plus the ground state of $\mathrm{H}$. In particular, we have generated curves for all states emanating from the ${ }^{2} S$ of $\mathrm{H}$ and the ${ }^{3} P,{ }^{1} D,{ }^{1} S,{ }^{5} S,{ }^{3} P\left(3 s^{2} 3 p^{1} 4 s^{1}\right),{ }^{1} P\left(3 s^{2} 3 p^{1} 4 s^{1}\right)$ states of the $\mathrm{Si}$ atom. Two more states, $\mathrm{a}^{2} \Delta$ and $\mathrm{a}^{4} \Delta$, originating from the $\mathrm{Si}^{3} D\left(3 s^{1} 3 p^{3}\right)$ have also been computed. Overall, 18 PECs have been constructed spanning an energy range of about $8 \mathrm{eV}$, at the same accuracy, we also report the potential energy curve of the $\mathrm{SiH}^{+}$ground state, $X^{1} \Sigma^{+}$. For all states studied we report absolute and binding energies, equilibrium distances, dipole moments, and usual spectroscopic parameters.

\section{METHODS AND COMPUTATIONAL DETAILS}

The one electron correlation-consistent basis set of Dunning and co-workers ${ }^{132}$ was used throughout the present work. In particular, for the Si atom the aug-cc-pV6Z basis set was employed, while for the $\mathrm{H}$ atom the plain cc-pV5Z. The final one electron generally contracted orbital space, $\left[9 s 8 p 6 d 5 f 4 g 3 h 2 i /_{S i} 5 s 4 p 3 d 2 f 1 g /{ }_{\mathrm{H}}\right], \quad$ contains 248 spherical Gaussian functions.

Our goal to construct accurate potential energy curves for all states examined dictated a multireference approach. 


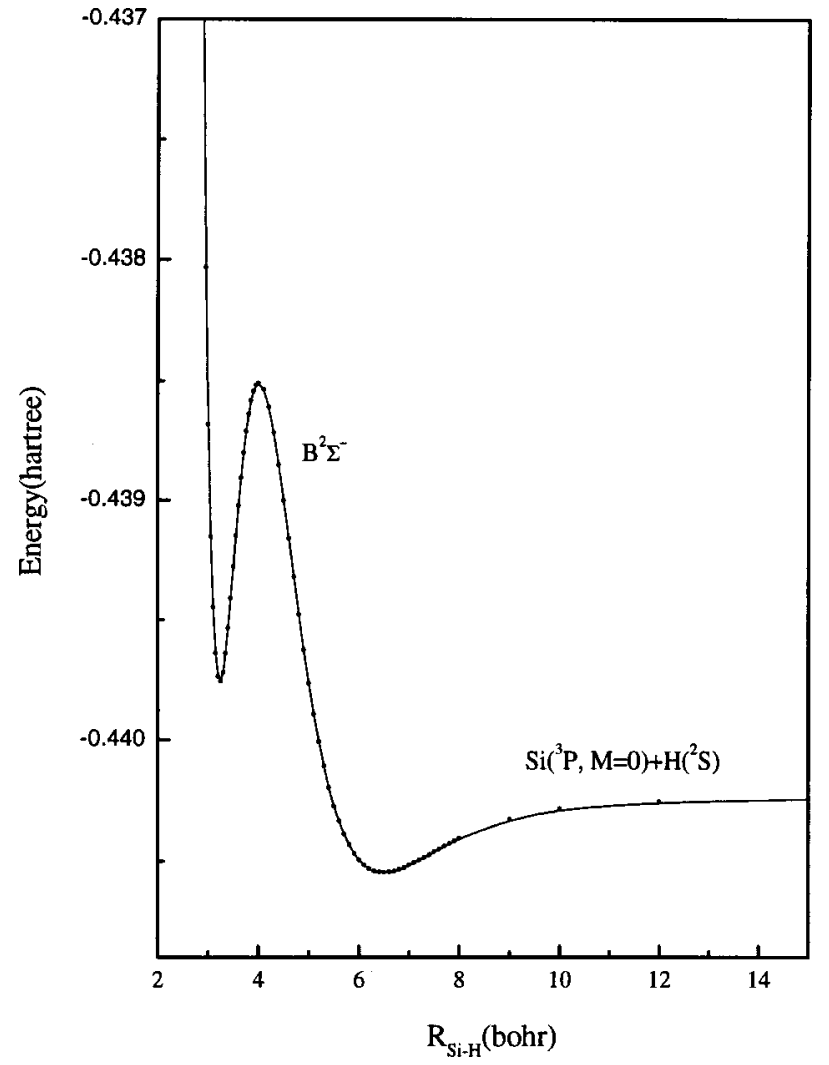

FIG. 2. Potential energy curve of the $B^{2} \Sigma^{-}$state of SiH at the MRCI level of theory.

Our zero-order function, namely a complete active space SCF $(=\mathrm{CASSCF})$, correlates at infinity to $\left(3 s+3 p_{\sigma, \pi}\right.$ $\left.+3 d_{\sigma, \pi, \delta}+4 s+4 p_{\sigma, \pi}\right)_{\mathrm{Si}}+(1 s)_{\mathrm{H}}=14$ atomic functions, providing a common orbital space for both valence- and Rydberg molecular states. By distributing the five "valence" (active) electrons among the 14 orbitals of the active space, configuration functions $(\mathrm{CF})$ of $|\Lambda|=0^{ \pm}, 1$, and 2 symmetry are generated. Additional valence correlation was obtained by single and double excitations out of the CASSCF space $(\mathrm{CASSCF}+1+2=\mathrm{MRCI})$, using at the same time the internal contraction (ic) scheme as implemented in the MOLPRO package. ${ }^{133}$ For the $X^{2} \Pi$ and the first excited $a^{4} \Sigma^{-}$states the coupled-cluster $\operatorname{CCSD}(\mathrm{T})$ method was also used for comparison purposes.

For excited states of ${ }^{2} \Sigma^{+}$and ${ }^{2} \Pi$ symmetry and for purely technical reasons, the state average ${ }^{134}$ methodology was followed. The large size of the one-electron basis set precludes significant basis-set superposition errors (BSSE). Indeed, the BSSE error of the ground $\mathrm{SiH} X^{2} \Pi$ state, calculated by the usual counterpoise technique, ${ }^{135}$ does not exceed $10 \mathrm{~cm}^{-1}(=0.03 \mathrm{kcal} / \mathrm{mol})$. Also, size nonextensivity errors are practically negligible due to the small number of active electrons.

Spectroscopic constants for the isotopomers ${ }^{28} \mathrm{Si}-{ }^{1,2} \mathrm{H}$ were extracted by obtaining rovibrational energy levels through a numerical Numerov solution of the nuclear Schrödinger equation, and then by a least-squares fit to the expansion $E(v, J)=\Sigma_{k, l} Y_{k l}\left(v+\frac{1}{2}\right)^{k}[J(J+1)]^{l}$, where $Y_{k l}$ represent the unknown spectroscopic constants. ${ }^{136}$

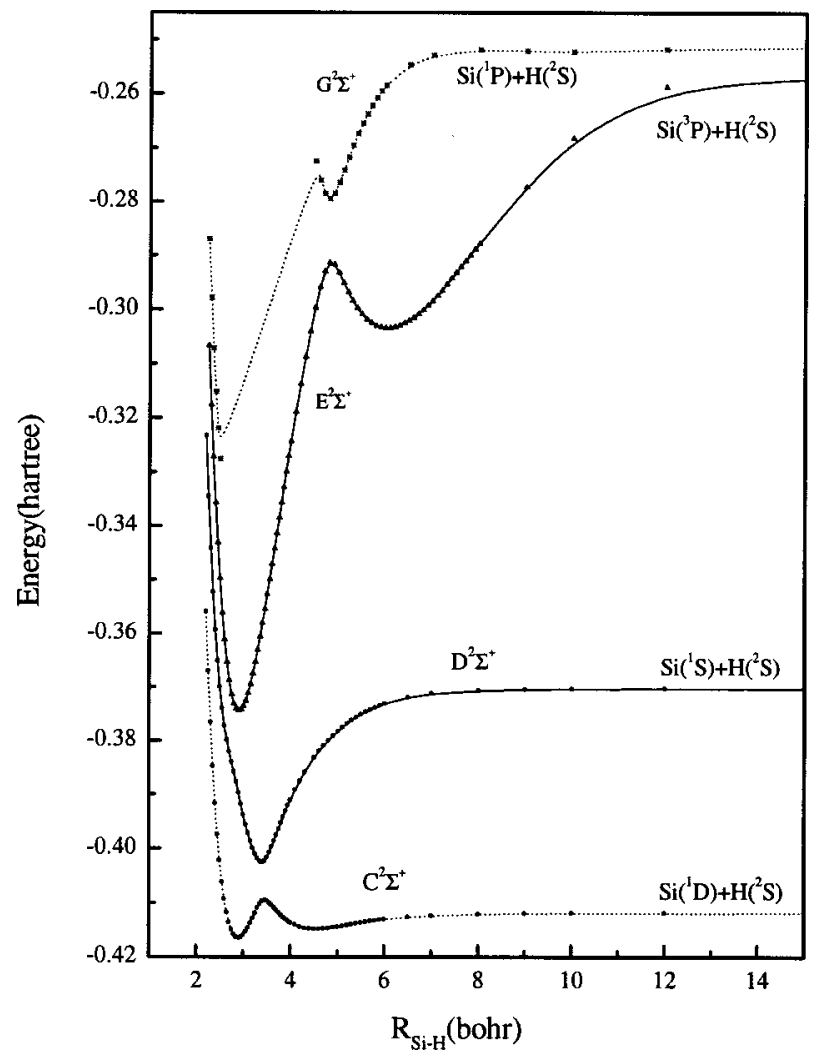

FIG. 3. Potential energy curves of the $C-, D-, E-$, and $G^{2} \Sigma^{+}$states of $\mathrm{SiH}$ at the MRCI level of theory.

\section{ATOMIC STATES}

Table II lists the MRCI absolute and relative (to ${ }^{3} P$ ) energies of the $\mathrm{Si}$ atom for all states involved in the formation of $\mathrm{SiH}$ either explicitly or implicitly. With the exception of the ${ }^{5} S$ state, the agreement between the experimental and theoretical energy levels is excellent. The theoretical level of the ${ }^{5} S$ state is lower than the experimental one by $0.165 \mathrm{eV}\left(=1331 \mathrm{~cm}^{-1}\right)$. This is attributed to the spin difference between the ${ }^{3} P$ and ${ }^{5} S$ states, which produces unbalanced correlation effects. It is noteworthy that the $\mathrm{Si}^{5} \mathrm{~S}$ state is not listed in the 1971 Moore tables. ${ }^{137}$

\section{RESULTS AND DISCUSSION}

Total energies $(E)$, binding energies $\left(D_{e}\right)$, equilibrium bond distances $\left(r_{e}\right)$, dipole moments $(\mu)$, and energy separations $\left(T_{e}\right)$ with respect to the ground $\mathrm{SiH}$ state are presented in Table III at different levels of theory. Table IV lists spectroscopic constants $\left(\omega_{e}, \omega_{e} x_{e}, \alpha_{e}, \bar{D}_{e}\right)$ of the isotopomers ${ }^{28} \mathrm{Si}-{ }^{1,2} \mathrm{H}$ for all bound states. Potential energy curves for all computed states of $\mathrm{SiH}$ and the ground state of $\mathrm{SiH}^{+}$are shown in Fig. 1.

In what follows we analyze the important characteristics of every state, contrasting them at the same time with the corresponding states of the $\mathrm{CH}$ molecule, ${ }^{139}$ isovalent to $\mathrm{SiH}$. 
TABLE V. $D_{e}(\mathrm{kcal} / \mathrm{mol}), r_{e}(\AA)$, and $T_{e}(\mathrm{kcal} / \mathrm{mol})$ values of $\mathrm{SiH}$ contrasted to the corresponding values of the $\mathrm{CH}$ system at the MRCI level of theory.

\begin{tabular}{|c|c|c|c|c|c|c|c|}
\hline \multirow[b]{2}{*}{ State } & \multicolumn{3}{|c|}{$\mathrm{CH}^{\mathrm{a}}$} & \multirow[b]{2}{*}{ State } & \multicolumn{3}{|c|}{$\mathrm{SiH}$} \\
\hline & $D_{e}$ & $r_{e}$ & $T_{e}$ & & $D_{e}$ & $r_{e}$ & $T_{e}$ \\
\hline$X^{2} \Pi$ & 83.37 & 1.1204 & 0.0 & $X^{2} \Pi$ & 73.55 & 1.5223 & 0.0 \\
\hline$a^{4} \Sigma^{-}$ & 66.03 & 1.0892 & 17.22 & $a^{4} \Sigma^{-}$ & 34.73 & 1.4974 & 38.77 \\
\hline$A^{2} \Delta$ & 45.54 & 1.1056 & 66.89 & $A^{2} \Delta$ & 22.28 & 1.5240 & 68.99 \\
\hline$B^{2} \Sigma^{-}$ & 8.59 & 1.1468 & 74.74 & $B^{2} \Sigma^{-}$ & 0.19 & 3.440 & 73.31 \\
\hline$C^{2} \Sigma^{+}$ & 20.98 & 1.1164 & 91.85 & $C^{2} \Sigma^{+}$ & 2.89 & 1.5338 & 88.37 \\
\hline$D^{2} \Sigma^{+}$ & 9.35 & 1.6635 & 136.11 & $D^{2} \Sigma^{+}$ & 20.29 & 1.7923 & 97.07 \\
\hline$c^{4} \Sigma^{-}$ & 22.31 & 1.7866 & 157.38 & $c^{4} \Sigma^{-}$ & 30.60 & 1.9453 & 134.01 \\
\hline$E^{2} \Pi$ & & 1.1437 & 169.68 & $F^{2} \Pi$ & & $\sim 1.43$ & $\sim 135$ \\
\hline$F^{2} \Pi$ & 75.22 & 1.3751 & 181.57 & $I^{2} \Pi$ & & & \\
\hline$G^{2} \Sigma^{+}$ & 69.30 & 1.1482 & 187.36 & $E^{2} \Sigma^{+}$ & 73.67 & 1.5374 & 114.71 \\
\hline$H^{2} \Pi$ & 61.03 & 1.3762 & 201.14 & $J^{2} \Pi$ & & & \\
\hline$I^{2} \Sigma^{+}$ & 57.85 & 1.2639 & 204.15 & $G^{2} \Sigma^{+}$ & & & \\
\hline \multirow[t]{4}{*}{$J^{2} \Delta$} & 48.92 & 1.6661 & 221.05 & $H^{2} \Delta$ & $\sim 54.8$ & $\sim 1.56$ & $\sim 147.2$ \\
\hline & & & & $e^{4} \Pi$ & 27.53 & 1.5081 & 160.90 \\
\hline & & & & $f^{4} \Delta$ & 17.86 & 1.5497 & 181.12 \\
\hline & & & & $g^{4} \Sigma^{+}$ & 1.60 & 1.5483 & 186.78 \\
\hline
\end{tabular}

${ }^{\mathrm{a}}$ Reference 139.

\section{A. $X^{2} \Pi$ state}

The bonding in the $X^{2} \Pi$ state can be clearly pictured by the following valence-bond Lewis (vbL) icon:

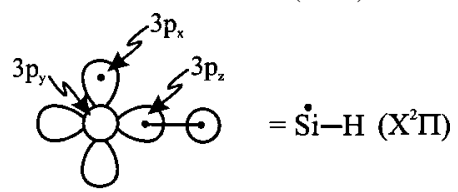

$\mathrm{Si}\left({ }^{3} \mathrm{P} ; \mathrm{M}=1\right) \quad \mathrm{H}\left({ }^{2} \mathrm{~S}\right)$

supported by the CASSCF equilibrium Mulliken populations $(\mathrm{Si} / \mathrm{H})$

$$
3 s^{1.80} 3 p_{z}^{0.96} 3 p_{x}^{0.98} 3 p_{y}^{0.06} 3 d^{0.12} / 1 s^{1.04} 2 p^{0.03} .
$$

The accurate experimental dissociation energy of $\operatorname{SiH}\left(X^{2} \Pi\right)$ is still questionable; its chronological evolution is given in detail by Larsson, ${ }^{113}$ who concluded that $3.012 \leqslant D_{0}$ $\leqslant 3.06$ ey. Using the experimental spectroscopic constants ${ }^{78}$ $\omega_{e}=2042.5229(8) \mathrm{cm}^{-1}$, and $\omega_{e} x_{e}=30.0552(5) \mathrm{cm}^{-1}$, the corresponding $D_{e}\left(=D_{0}+\omega_{e} / 2-\omega_{e} x_{e} / 4\right)$ inequality (in kcal/ mol) is $72.35 \leqslant D_{e} \leqslant 73.46$. In Table III we report $D_{e}$ $=73.55,73.73$, and $73.57 \mathrm{kcal} / \mathrm{mol}$ at the MRCI, MRCI + Davidson correction $(+Q)$, and $\operatorname{CCSD}(\mathrm{T})$ levels of theory, respectively. According to Feller and Dixon, ${ }^{130}$ scalar relativistic effects $\Delta E(\mathrm{sr})$ decrease the binding energy by $\Delta E(\mathrm{sr})=0.1 \mathrm{kcal} / \mathrm{mol}$, while core-valence $\Delta E(\mathrm{cv})$ contributions do not affect the $D_{e}$ value. ${ }^{130}$ Taking into account the experimental atomic ${ }^{137}$ and molecular ${ }^{84}$ spin-orbit splittings, $\quad \operatorname{Si}\left({ }^{3} P_{2}-{ }^{3} P_{0}\right)=223.31 \mathrm{~cm}^{-1}, \quad \operatorname{SiH}\left({ }^{2} \Pi_{ \pm 3 / 2}-^{2} \Pi_{ \pm 1 / 2}\right)$ $=151.5508 \mathrm{~cm}^{-1}$, the binding energy should also be corrected by

$$
\begin{aligned}
\Delta E(\mathrm{so})= & \frac{E\left({ }^{2} \Pi_{3 / 2}\right) \times 4+E\left({ }^{2} \Pi_{1 / 2}\right) \times 2}{6} \\
& -\frac{E\left({ }^{3} P_{0}\right) \times 1+E\left({ }^{3} P_{1}\right) \times 3+E\left({ }^{3} P_{2}\right) \times 5}{9}
\end{aligned}
$$

$=101.0338-149.680 \quad 07 \mathrm{~cm}^{-1}=-48.646 \mathrm{~cm}^{-1}(=-0.14$ $\mathrm{kcal} / \mathrm{mol})$. Finally, including the BSSE correction of $-0.03 \mathrm{kcal} / \mathrm{mol}$ we obtain $D_{e}($ corrected $)=D_{e}(\mathrm{MRCI})$ $+\Delta \mathrm{E}(\mathrm{so})+\Delta \mathrm{E}(\mathrm{sr})+\Delta \mathrm{E}(\mathrm{cv})+\Delta \mathrm{E}(\mathrm{BSSE})=73.55-0.27$ $=73.28 \mathrm{kcal} / \mathrm{mol}$, in complete agreement with the (corrected) results of Feller and Dixon. ${ }^{130}$ Our MRCI bond distance, $r_{e}$ $=1.5223 \AA$, obtained by a Dunham analysis, is by $0.0026 \AA$ longer as compared to the experimental value of $1.51966(7)$ $\AA{ }^{78}$ probably because the core-valence correlation effects ${ }^{96}$ are not included in the present calculations.

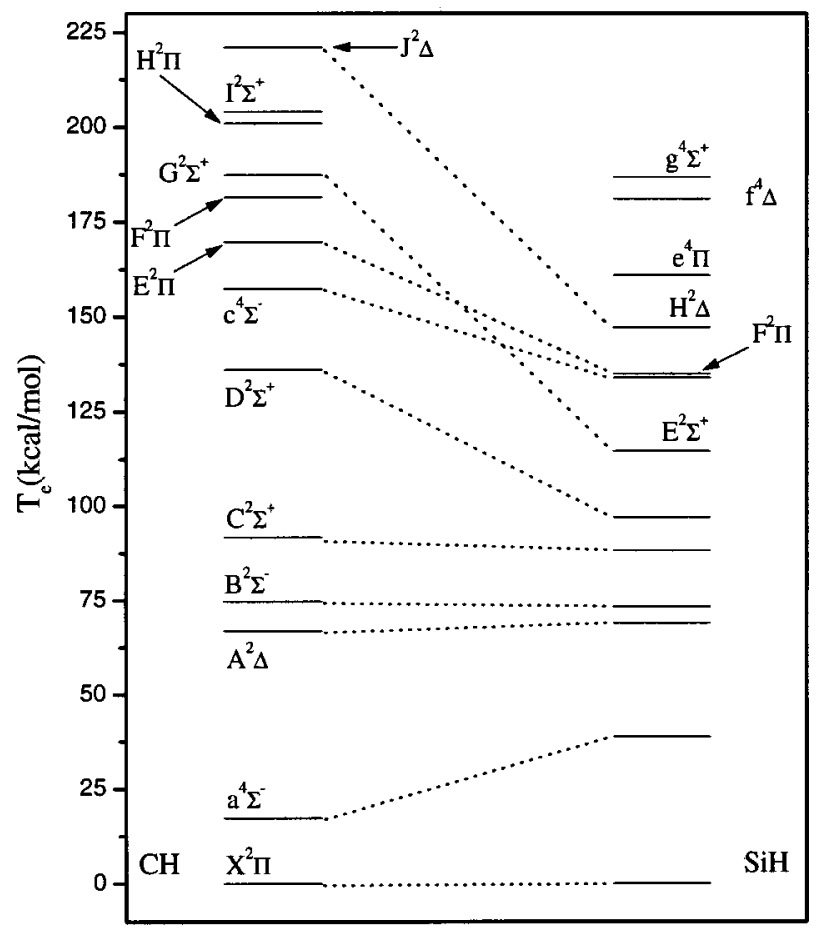

FIG. 4. Relative energy levels of the isovalent species of $\mathrm{CH}$ and $\mathrm{SiH}$ at the MRCI level of theory. Dotted lines connect corresponding states between the two species. 
By solving the radial Schrödinger equation numerically, the rovibrational levels are obtained; it is found that the $\mathrm{SiH}\left(X^{2} \Pi\right)$ potential (Fig. 1) can sustain 20 vibrational levels, $v=0-19$. In particular, for the vibrational transitions $0-1,1-2$, and 2-3 we predict 1972.84, 1902.30, and $1831.54 \mathrm{~cm}^{-1}$, respectively, in excellent agreement with the corresponding experimental values, ${ }^{79} 1971.0413$, 1900.0585, and $1829.8196 \mathrm{~cm}^{-1}$, reflecting the accuracy of the potential energy function.

\section{B. $a^{4} \Sigma^{-}$and $c^{4} \Sigma^{-}$states}

In essence, for both states above there are no experimental findings (but see below). The $a^{4} \Sigma^{-}$state correlates to $\mathrm{Si}\left({ }^{3} P ; M=0\right)+\mathrm{H}\left({ }^{2} S\right)$, Fig. 1 . The CASSCF leading equilibrium configuration is $\sim 0.97\left|1 \sigma^{2} 2 \sigma^{1} 1 \pi_{x}^{1} 1 \pi_{y}^{1}\right\rangle$ (counting only "valence" electrons), with $1 \sigma \sim 0.72(3 s)+0.30\left(3 p_{z}\right)$ $+0.66(1 s)$, and $2 \sigma \sim 0.62(3 s)-0.67\left(3 p_{z}\right)-0.54(1 s)$. The atomic CASSCF Mulliken atomic populations at infinity and equilibrium are

$$
\begin{array}{ll}
r_{\infty}: & 3 s^{1.91} 3 p_{z}^{0.05} 3 p_{x}^{0.99} 3 p_{y}^{0.99} 3 d^{0.06} / 1 s^{1.0}, \\
r_{e}: & 3 s^{1.45} 3 p_{z}^{0.56} 3 p_{x}^{0.99} 3 p_{y}^{0.99} 3 d^{0.09} / 1 s^{0.90} 2 p^{0.04} .
\end{array}
$$

Upon bonding, a strong $3 s 3 p_{z}$ hybridization occurs caused by the promotion of $0.46 e^{-}$from the $\mathrm{Si} 3 s$ to the $3 p_{z}$ orbital; thus, the in situ $\mathrm{Si}$ atom acquires a partial ${ }^{5} S$ character. The emerging bonding picture can be described as a superposition of two limiting vbL icons

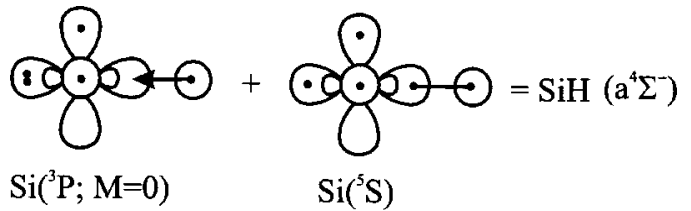

The $D_{e}$ value obtained at the $\mathrm{MRCI}, \mathrm{MRCI}+\mathrm{Q}$, and CCSD(T) level is practically the same (Table III), the MRCI value being $34.73 \mathrm{kcal} / \mathrm{mol}$ compared to $32.49 \mathrm{kcal} / \mathrm{mol}$ at the SCF level.

An experimental $a^{4} \Sigma^{-} \leftarrow X^{2} \Pi$ separation of $\sim 5000 \mathrm{~cm}^{-1}(=14.3 \mathrm{kcal} / \mathrm{mol})$ has been reported by Park, ${ }^{66}$ based on a separation $X^{2} \Pi \rightarrow b^{4} \Pi$ (repulsive) of 24800 $\mathrm{cm}^{-1}$, and to the observed transition $b^{4} \Pi \leftarrow a^{4} \Sigma^{-}$of about $20000 \mathrm{~cm}^{-1}$. Our $T_{e}\left(a^{4} \Sigma^{-} \leftarrow X^{2} \Pi\right)=13559 \mathrm{~cm}^{-1}$ $(=38.77 \mathrm{kcal} / \mathrm{mol})$ at the MRCI level, leaves no doubt that the experimental value is wrong. Our corresponding vertical transitions $b^{4} \Pi \leftarrow X^{2} \Pi$, and $b^{4} \Pi \leftarrow a^{4} \Sigma^{-}$are 48607 and $35913 \mathrm{~cm}^{-1}$, respectively.

The $c^{4} \Sigma^{-}$state traces its origin to $\mathrm{Si}\left({ }^{5} S\right)+\mathrm{H}\left({ }^{2} S\right)$, and in contrast to the $a^{4} \Sigma^{-}$is not dominated by a single configuration function. Indeed, the leading equilibrium CASSCF configurations are

$$
\begin{gathered}
\left|c^{4} \Sigma^{-}\right\rangle \sim \mid \\
-0.86 \times 1 \sigma^{2} 2 \sigma^{1}-0.39 \times 2 \sigma^{2} 3 \sigma^{1} \\
\left.\left.-0.19 \times 2 \sigma^{1} 3 \sigma^{2}\right) 1 \pi_{x}^{1} 1 \pi_{y}^{1}\right\rangle,
\end{gathered}
$$

with $1 \sigma \sim 0.41(3 s)-0.57\left(3 p_{z}\right)-0.70(1 s), \quad 2 \sigma \sim 0.90(3 s)$ $+0.12\left(3 p_{z}\right)+0.35(1 s), \quad 3 \sigma \sim 0.20(3 s)+0.98\left(3 p_{z}\right)$ $-0.76(1 s)$, and the following atomic CASSCF populations: $3 s^{1.21} 3 p_{z}^{0.76} 3 p_{x}^{0.98} 3 p_{y}^{0.98} 3 d^{0.10} / 1 s^{0.96} 2 p^{0.02}$. Based on the atomic distributions we can claim that the in situ $\mathrm{Si}$ atom is in a ${ }^{5} S$ state, so the bonding can be described by the icon

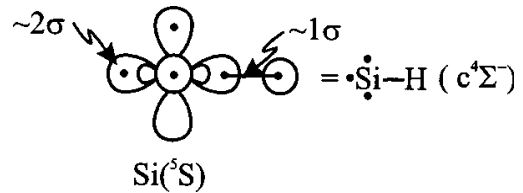

At the MRCI level $T_{o}\left(c^{4} \Sigma^{-} \leftarrow X^{2} \Pi\right)=T_{e}+1 / 2\left[\omega_{e}\left(c^{4} \Sigma^{-}\right)\right.$ $\left.-\omega_{e}\left(X^{2} \Pi\right)\right]=134.0-1.14=132.9 \mathrm{kcal} / \mathrm{mol}($ Tables III and IV) is in very good agreement with the corresponding experimental $T_{o}$ separation of $46000 \mathrm{~cm}^{-1}(=131.52 \mathrm{kcal} / \mathrm{mol}){ }^{66}$ With respect to $\mathrm{Si}\left({ }^{5} S\right)+\mathrm{H}\left({ }^{2} S\right), D_{e}=30.60(30.74) \mathrm{kcal} / \mathrm{mol}$ and $r_{e}=1.945(1.943) \AA$ at the $\operatorname{MRCI}(+\mathrm{Q})$ level, Table III.

\section{C. $A^{2} \Delta$ state}

As the PEC of Fig. 1 shows, the $A^{2} \Delta$ state correlates to $\mathrm{Si}\left({ }^{1} D ; M= \pm 2\right)+\mathrm{H}\left({ }^{2} S\right)$. The dominant CASSCF configurations are

$$
\left|A^{2} \Delta\right\rangle \sim 0.67\left(\left|1 \sigma^{2} 2 \sigma^{1} 1 \pi_{x}^{2}\right\rangle-\left|1 \sigma^{2} 2 \sigma^{1} 1 \pi_{y}^{2}\right\rangle\right),
$$

dictating a $\sigma$ bond as the following vbL icon suggests

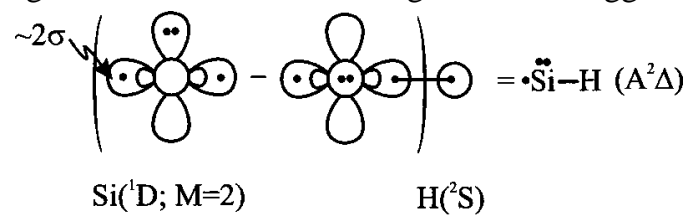

very similar to that of the $\mathrm{CH} A^{2} \Delta$ state. $^{139}$ The above picture is corroborated by the atomic equilibrium and asymptotic CASSCF distributions

$$
\begin{array}{ll}
r_{\infty}: & 3 s^{1.91} 3 p_{z}^{0.05} 3 p_{x}^{1.0} 3 p_{y}^{1.0} 3 d^{0.07} / 1 s^{1.0}, \\
r_{e}: & 3 s^{1.55} 3 p_{z}^{0.50} 3 p_{x}^{0.96} 3 p_{y}^{0.96} 3 d^{0.10} / 1 s^{0.88} 2 p^{0.04},
\end{array}
$$

indicating a promotion of $0.36 e^{-}$from the $\mathrm{Si} 3 s$ to $3 p_{z}$ resulting in a $3 s 3 p_{z}$ hybrid orbital, with the synchronous transfer to that hybrid of $0.09 e^{-}$from the $1 s$ hydrogen function.

Although the experimental dissociation energy of the $A^{2} \Delta$ state is not explicitly reported in the literature, it can be deduced by the relationship $D_{e}\left(A^{2} \Delta\right)=D_{e}\left(X^{2} \Pi\right)$ $+\Delta E\left(\mathrm{Si} ;{ }^{1} D \leftarrow{ }^{3} P\right)-T_{e}\left(A^{2} \Delta \leftarrow X^{2} \Pi\right)$. Employing the experimental values (in $\mathrm{kcal} / \mathrm{mol}), \quad 72.35 \leqslant D_{e}\left(X^{2} \Pi\right)$ $\leqslant 73.46,{ }^{113} \quad \Delta E\left(\mathrm{Si} ;{ }^{1} D \leftarrow{ }^{3} P\right)=17.58,{ }^{137}$ and $T_{e}\left(A^{2} \Delta\right.$ $\left.\leftarrow X^{2} \Pi\right)=69.35,{ }^{65}$ one obtains $20.58 \leqslant D_{e}^{\exp }\left(A^{2} \Delta\right) \leqslant 21.69$. This range of values should be contrasted with our $D_{e}$ $=22.28 \mathrm{kcal} / \mathrm{mol}$ at the MRCI level, Table III. Now, the $\operatorname{MRCI}(+\mathrm{Q}) r_{e}=1.5240(1.5237) \AA$ is longer by $0.0042 \AA$ than the latest experimental value of $1.5197816(21) \AA{ }^{84}$ As already mentioned, this discrepancy is rather caused by core-valence correlation effects not taken into account in the present study.

\section{D. $B^{2} \Sigma^{-}$state}

By coupling the electrons of the $a^{4} \Sigma^{-}$state into a doublet, the "quasirepulsive" $B^{2} \Sigma^{-}$state is obtained, correlating to $\operatorname{Si}\left({ }^{3} P ; M=0\right)+\mathrm{H}\left({ }^{2} S\right)$, Figs. 1 and 2 . By following its PEC (Fig. 2) more closely, two minima are observed, the first 
one at $r_{e}=6.5 \mathrm{bohr}$, displaying an interaction of just $66.5 \mathrm{~cm}^{-1}(=0.19 \mathrm{kcal} / \mathrm{mol})$, clearly of van der Waals origin. As we move closer, an energy barrier of $1.28 \mathrm{kcal} / \mathrm{mol}(r=4.0 \mathrm{bohr})$ with respect to the van der Waals minimum is developed, followed by a second, non-van der Waals minimum of $0.79 \mathrm{kcal} / \mathrm{mol}$ at $r_{e}=1.715 \AA$. The situation is closely analogous to the $B^{2} \Sigma^{-}$state of $\mathrm{CH} ;{ }^{139}$ hence, it is conjectured that the second $\mathrm{SiH}$ minimum is caused by the intervention of $a^{2} \Sigma^{-}$state correlating to $\mathrm{Si}\left({ }^{3} D\right)+\mathrm{H}\left({ }^{2} S\right)$.

\section{E. $b^{4} \Pi$ and $e^{4} \Pi$ states}

The $b^{4} \Pi$ is a purely Pauli repulsive state succinctly described by the picture

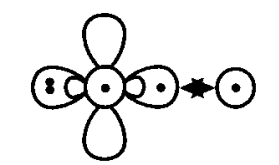

$\left(b^{4} \Pi\right)$

$$
\mathrm{Si}\left({ }^{3} \mathrm{P} ; \mathrm{M}=1\right) \quad \mathrm{H}\left({ }^{2} \mathrm{~S}\right)
$$

and displaying a van der Waals interaction of $8.1 \mathrm{~cm}^{-1}$ at about 10 bohr. The corresponding $\mathrm{CH}$ values are $4.5 \mathrm{~cm}^{-1}$ at $r=9$ bohr. ${ }^{139}$ It is interesting to observe that an avoided crossing occurs at 2.4 bohr with the repulsive part of the $e^{4} \Pi$ Rydberg state (see below), tracing its lineage to $\mathrm{Si}\left(3 s^{2} 3 p^{1} 4 s^{1},{ }^{3} P ; M= \pm 1\right)+\mathrm{H}\left({ }^{2} S\right)$, Fig. 1 .

Now, the $e^{4} \Pi$ (Rydberg) state shows a repulsive character up to $6.5 \mathrm{bohr}$, giving rise to an energy barrier of $1.72 \mathrm{kcal} / \mathrm{mol}$. Passing this point the PEC plummets, resulting in an equilibrium distance $r_{e}=1.5081 \AA$ and $D_{e}=27.53 \mathrm{kcal} / \mathrm{mol}$ with respect to the adiabatic products. The dominant equilibrium MRCI configuration and corresponding Mulliken atomic populations are $\left|e^{4} \Pi\right\rangle \sim 0.96\left|1 \sigma^{2} 2 \sigma^{1} 3 \sigma^{1} 1 \pi_{x}^{1}\right\rangle, \quad$ and $\quad(3 s+4 s)^{2.45} 3 p_{z}^{0.64}$ $3 p_{x}^{0.99} 3 p_{y}^{0.04} 3 d^{0.12} / 1 s^{0.73} 2 p^{0.04}$, showing a significant total transfer of $0.23 e^{-}$from $\mathrm{H}$ to $\mathrm{Si}$, and in particular to the $3 p_{z}$ orbital, causing the creation of a half (one electron) $\sigma$ bond.

\section{F. $C^{2} \Sigma^{+}, D^{2} \Sigma^{+}, E^{2} \Sigma^{+}$, and $G^{2} \Sigma^{+}$states}

The $C$ and $D^{2} \Sigma^{+}$states correlate adiabatically to

$$
\begin{aligned}
\operatorname{Si}\left({ }^{1} D ; M=0\right)= & \frac{1}{\sqrt{6}}\left[2\left|3 s^{2} 3 p_{z}^{2}\right\rangle-\left|3 s^{2} 3 p_{x}^{2}\right\rangle\right. \\
& \left.-\left|3 s^{2} 3 p_{y}^{2}\right\rangle\right],
\end{aligned}
$$

and

$$
\operatorname{Si}\left({ }^{1} S\right)=\frac{1}{\sqrt{3}}\left[\left|3 s^{2} 3 p_{z}^{2}\right\rangle+\left|3 s^{2} 3 p_{x}^{2}\right\rangle+\left|3 s^{2} 3 p_{y}^{2}\right\rangle\right],
$$

respectively. The $C^{2} \Sigma^{+}$PEC presents two minima: one at $r_{e}=2.40 \AA$ and an interaction energy of $1.87 \mathrm{kcal} / \mathrm{mol}$, maintaining in essence the character of the asymptote, and a second one at $r_{e}=1.534 \AA$ with an interaction energy of 2.89 $\mathrm{kcal} / \mathrm{mol}$ with respect to the asymptotic products, Fig. 3 . The second minimum results from an avoided crossing with the $D^{2} \Sigma^{+}$state, so the internal bond strength of the $C$ state is $2.89+\Delta E\left[\operatorname{Si}\left({ }^{1} S\right) \leftarrow \operatorname{Si}\left({ }^{1} D\right)\right]=29.0 \mathrm{kcal} / \mathrm{mol}$. The minimum (equilibrium) of the $D^{2} \Sigma^{+}$state is located at the top of the avoided crossing $(r=1.792 \AA)$, corresponding to $D_{e}$ $=20.3 \mathrm{kcal} / \mathrm{mol}$ with respect to $\operatorname{Si}\left({ }^{1} S\right)+\mathrm{H}\left({ }^{2} S\right)$.

Experimental results exist for, presumably, two states tagged $B$ - and $C^{2} \Sigma^{+}$(see Ref. 67, and Table I): $T_{e}^{\exp }(C$ $\leftarrow X)=31832.4 \mathrm{~cm}^{-1}, \quad r_{e}=3.8_{5} \AA, \quad$ and $\quad T_{e}^{\exp }(B \leftarrow X)$ $=31842.2 \mathrm{~cm}^{-1}, r_{e}=1.61_{8} \AA$. We believe that the $B$ - and $C^{2} \Sigma^{+}$experimental states correspond to the two minima of our $C^{2} \Sigma^{+}$state. Indeed, at $r_{e}=2.40$ and $1.53 \AA$ mentioned above, the corresponding $T_{e}$ values are $89.4 \mathrm{kcal} / \mathrm{mol}$ $\left(=31263 \mathrm{~cm}^{-1}\right)$, and $88.4 \mathrm{kcal} / \mathrm{mol}\left(=30918 \mathrm{~cm}^{-1}\right)$, respectively, with respect to the $X^{2} \Pi$ state. Finally, it is worth mentioning that the PEC morphologies and their explanation of the $C$ - and $D^{2} \Sigma^{+} \mathrm{SiH}$ states are, mutatis mutandis, identical to the $C$ - and $D^{2} \Sigma^{+}$states of $\mathrm{CH} .{ }^{139}$

The $E^{2} \Sigma^{+}$state correlates to the Rydberg $\mathrm{Si}\left({ }^{3} P ; M\right.$ $=0)+\mathrm{H}\left({ }^{2} S\right)$ fragments, with its PEC presenting a local $(l)$ and a global $(g)$ minima, Fig. 3. The leading CAS configurations for the $l$ - and $g$-minima are

$$
\begin{aligned}
\left|E^{2} \Sigma^{+} ; l\right\rangle \sim & 0.60\left|1 \sigma^{2} 2 \sigma^{1} 3 \sigma^{2}\right\rangle+0.56\left|1 \sigma^{2} 2 \sigma^{2} 3 \sigma^{1}\right\rangle \\
& -0.16\left|1 \sigma^{2} 2 \sigma^{2} 4 \sigma^{1}\right\rangle,
\end{aligned}
$$

with

$$
\begin{aligned}
& 1 \sigma \sim 3 s, 2 \sigma \sim 0.44\left(3 p_{z}\right)+0.79(1 s), \\
& 3 \sigma \sim 1.0\left(3 p_{z}\right)-0.45(1 s) \\
& 4 \sigma \sim 4 s \\
& \quad\left|E^{2} \Sigma^{+} ; g\right\rangle \sim 0.76\left|1 \sigma^{2} 2 \sigma^{2} 3 \sigma^{1}\right\rangle \\
& \quad+0.54\left|1 \sigma^{2} 2 \sigma^{2} 4 \sigma^{1}\right\rangle
\end{aligned}
$$

with

$$
\begin{aligned}
& 1 \sigma \sim 0.83(3 s)+0.25\left(3 p_{z}\right)+0.56(1 s), \\
& 2 \sigma \sim 0.58(3 s)-0.68\left(3 p_{z}\right)-0.59(1 s), \\
& 3 \sigma \sim 0.23(3 s)+0.77\left(3 p_{z}\right)-0.52(1 s), \quad 4 \sigma \sim 4 s .
\end{aligned}
$$

The $r_{e}$ and $D_{e}$ parameters of the $l$ - and $g$-minima are (in $\AA$ and $\mathrm{kcal} / \mathrm{mol}) 3.18,29.1$, and $1.537,73.7$, respectively. The bonding in the $l$-min can be attributed to the $2 \sigma$ orbital, the $3 \sigma$ being simply the orthogonal counterpart of the $2 \sigma$ with no practical participation of the $3 s$ or $4 s$ atomic $\mathrm{Si}$ orbitals. It is interesting that the dipole moment is $\mu=$ $-9.55 \mathrm{D}$, with $0.25 e^{-}$transferred from the $\mathrm{Si}$ to the $\mathrm{H}$ atom. Due to an avoided crossing of the $E$ - with the $G^{2} \Sigma^{+}$(Rydberg) state at 4.8 bohr, an energy barrier of about 7.6 $\mathrm{kcal} / \mathrm{mol}$ is created with respect to the $l$-minimum (Fig. 3); thus, the $g-E^{2} \Sigma^{+}$minimum correlates diabatically to $\mathrm{Si}\left(3 s^{2} 3 p^{1} 4 s^{1}{ }^{1} P\right)+\mathrm{H}\left({ }^{2} S\right)$. A second avoided crossing is observed in the repulsive part of the $E$ state with the previously discussed $D^{2} \Sigma^{+}$state, and close to 2.8 bohr, Fig. 3. From the CAS configurations and the explicit form of the orbitals, we can speak of two "bonding" orbitals, namely the $1 \sigma$ and $2 \sigma$, with the $3 \sigma$ and $4 \sigma(\sim 4 s)$ carrying the spin symmetry. Overall, less than $0.1 e^{-}$are transferred from Si to $\mathrm{H}$, resulting in a (relative) negative dipole moment ten times smaller than that of the $l$-minimum. Finally, the similarity 
between the $\mathrm{SiH} E^{2} \Sigma^{+}$state and the corresponding $\mathrm{CH}$ state $\left(G^{2} \Sigma^{+}\right)$, is remarkable: instead the CH PEC barrier is 9.1 $\mathrm{kcal} / \mathrm{mol}$ and the $g-D_{e}=69.3 \mathrm{kcal} / \mathrm{mol} .{ }^{139}$

Due to severe technical difficulties, only part of the PEC of the Rydberg $G^{2} \Sigma^{+}$state has been computed, Fig. 3. The only certain thing that can be said about the $G$ state is that its $l$-minimum occurs at $4.8 \mathrm{bohr}$ (the point of the avoided crossing), giving rise to $D_{e}=17.7 \mathrm{kcal} / \mathrm{mol}$ with respect to $\mathrm{Si}\left({ }^{1} P\right)+\mathrm{H}\left({ }^{2} S\right)$. A global minimum surely exists as indicated from a few calculated energy points in the PEC's repulsive part, and the work of Lewerenz et al. ${ }^{105(a)}$

\section{G. $F^{2} \Pi, I^{2} \Pi$, and $J^{2} \Pi$ states}

None of the PECs of the above SiH states has been fully calculated in the present work due to severe technical problems, with the most complete among the three being that of the $F^{2} \Pi$ state, Fig. 1.

The repulsive part of the $F^{2} \Pi$ state shows a van der Waals interaction of $56.8 \mathrm{~cm}^{-1}$ correlating to $\operatorname{Si}\left({ }^{1} D ; M=\right.$ $\pm 1)=\left|3 s^{2} 3 p_{z}^{1} 3 \bar{p}_{x}^{1}\right\rangle-\left|3 s^{2} 3 \bar{p}_{z}^{1} 3 p_{x}^{1}\right\rangle+\mathrm{H}\left({ }^{2} S\right)$. This character is preserved along the PEC and up to $3.15 \mathrm{bohr}$, where an avoided crossing takes place with the incoming $I^{2} \Pi$ Rydberg state. The resulting energy barrier has a height of 9.1 $\mathrm{kcal} / \mathrm{mol}$ with respect to the minimum; therefore, the latter acquires the character of the $I^{2} \Pi$ Rydberg state, and thus diabatically traces its lineage to the Rydberg $\mathrm{Si}\left(3 s^{2} 3 p^{1} 4 p^{1},{ }^{3} D\right), 5.95 \mathrm{eV}$ above the $\mathrm{Si}^{3} P$ state, Table II. Assuming that our lowest calculated point corresponds to the minimum, we predict $r_{e}=1.43 \AA$ and $T_{e}=135 \mathrm{kcal} / \mathrm{mol}$, in very good agreement with the experimental $T_{o}$ value of $46700 \pm 10 \mathrm{~cm}^{-1}(=133.5 \mathrm{kcal} / \mathrm{mol}){ }^{82}$ At $r_{e}$ the dominant CASSCF configuration is $\sim 0.95\left|1 \sigma^{2} 2 \sigma^{2} 2 \pi_{x}^{1}\right\rangle$, with the following atomic Mulliken densities $3 s^{1.80} 3 p_{z}^{1.04} 4 p_{x}^{1.02} 3 p_{y}^{0.05} 3 d^{0.13} / 1 s^{0.94} 2 p^{0.02}$ displaying clearly the in situ ${ }^{3} D$ character of the $\mathrm{Si}$ atom. Notice that the bond length $r_{e}=1.43 \AA$ of the Rydberg minimum is the shortest of all states studied, $0.09 \AA$ shorter than the $X$ state, with a diabatic bond strength [with respect to $\mathrm{Si}\left({ }^{3} D\right)$ ] of $75.8 \mathrm{kcal} /$ mol. The bonding can be described by the diagram

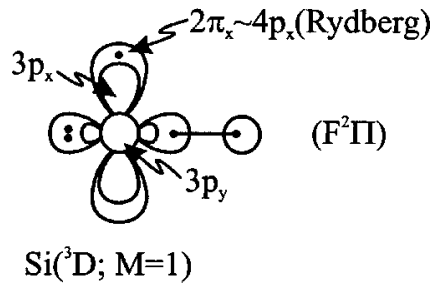

indicating a single $\sigma$ bond, with no participation of the symmetry-carrying Rydberg $2 \pi_{x} \sim 4 p_{x}$ electron, and, that, in essence, the $\mathrm{H}$ atom binds to a $\mathrm{Si}^{+}{ }^{2} P$ state resulting in $\mathrm{SiH}^{+}$ $X^{1} \Sigma^{+}$state plus a loosely bound $\pi$ electron.

The $I^{2} \Pi$ Rydberg state correlates to $\mathrm{Si}\left(3 s^{2} 3 p^{1} 4 s^{1},{ }^{3} P ; M= \pm 1\right)+\mathrm{H}\left({ }^{2} S\right)$, with its PEC showing a broad minimum at $r_{e}=3.175 \AA$ and $D_{e}=33.6 \mathrm{kcal} / \mathrm{mol}$ with respect to the asymptote. The interaction of the $I$ - and $J^{2} \Pi$ states gives rise to the first avoided crossing of the $I$ state at about $4.2 \mathrm{bohr}$, thus creating an energy barrier of 10.9 $\mathrm{kcal} / \mathrm{mol}$ with respect to the minimum. A second avoided crossing previously discussed with the $F$ state occurs at 3.15 bohr. According to the present results and the results of Lewerenz et al. ${ }^{105(\mathrm{a})}$ the complete $I^{2} \Pi$ PEC should exhibit three minima at distances 3.175 (present work), $\sim 1.78,{ }^{105(\mathrm{a})}$ and $1.52 \AA .{ }^{105(\mathrm{a}) \tilde{O}}$

The $J^{2} \Pi$ Rydberg state correlates to $\mathrm{Si}\left(3 s^{2} 3 p^{1} 4 s^{1},{ }^{1} P ; M= \pm 1\right)+\mathrm{H}\left({ }^{2} S\right)$ with a few calculated points shown in Fig. 1.

\section{H. $H^{2} \Delta$ state}

A part of the PEC's $H^{2} \Delta$ is shown in Fig. 1, correlating to

$$
\begin{aligned}
\operatorname{Si}\left({ }^{3} D ; M=\right. & \pm 2) \\
\sim & 0.54\left|3 s^{1} 3 p_{z}^{1}\left(3 p_{x}^{2}-3 p_{y}^{2}\right)\right\rangle \\
& -0.41\left|3 s^{2} 3 p_{z}^{1} 3 d_{x^{2}-y^{2}}^{1}\right\rangle+0.21 \mid 3 s^{2}\left(3 p_{x}^{1} 3 d_{x z}^{1}\right. \\
& \left.-3 p_{y}^{1} 3 d_{y z}^{1}\right\rangle+\mathrm{H}\left({ }^{2} S\right) .{ }^{140}
\end{aligned}
$$

Close to equilibrium, the dominant configurations are

$\left|H^{2} \Delta\right\rangle \sim 0.61\left|1 \sigma^{2} 2 \sigma^{2} 1 \delta_{+}^{1}\right\rangle+0.24\left|1 \sigma^{1} 2 \sigma^{2}\left(1 \pi_{x}^{2}-1 \pi_{y}^{2}\right)\right\rangle$,

following the atomic character. Our numerical results, Table III, cannot be considered reliable enough, since the reference orbitals originate from a state average procedure of four ${ }^{2} \Sigma^{+}$ states.

\section{I. $f^{4} \Delta$ and $g^{4} \Sigma^{+}$states}

Only part of the PEC's $f^{4} \Delta$ state has been computed due to technical difficulties, Fig. 1. Adiabatically it should correlate to $\mathrm{Si}\left(3 s^{1} 3 p^{3},{ }^{3} D ; M= \pm 2\right)+\mathrm{H}\left({ }^{2} S\right)$; however, the equilibrium character implies the entanglement of the $\mathrm{Si}\left(3 s^{2} 3 p^{1} 4 p^{1},{ }^{3} D\right)$ Rydberg state through an (assumed) avoided crossing. At equilibrium ( $r_{e}$ $=1.550 \AA)$, the dominant MRCI configurations read $\left|f^{4} \Delta\right\rangle \sim 0.67\left|1 \sigma^{2} 2 \sigma^{1}\left(1 \pi_{x}^{1} 2 \pi_{x}^{1}-1 \pi_{y}^{1} 2 \pi_{y}^{1}\right)\right\rangle$ with $1 \sigma \sim 0.85$ $(3 s)+0.24\left(3 p_{z}\right)+0.58(1 s), 2 \sigma \sim 0.60(3 s)-0.73\left(3 p_{z}\right)-0.62(1 \mathrm{~s})$, $1 \pi \sim 3 p_{\pi}, 2 \pi \sim 4 p_{\pi}$, and populations

$$
\begin{gathered}
(3 s+4 s)^{1.56} 3 p_{z}^{0.54}\left(3 p_{x}+4 p_{x}\right)^{0.95} 3 d_{x z}^{0.05}\left(3 p_{y}\right. \\
\left.+4 p_{y}\right)^{0.95} 3 d_{y z}^{0.05} 3 d^{0.16} / 1 s^{0.78} 2 p^{0.04} .
\end{gathered}
$$

A bonding picture consistent with the above orbitals and distributions is the following:

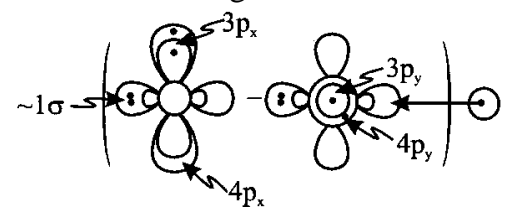

A total of $0.17 e^{-}$are transferred from $\mathrm{H}$ to the $\mathrm{Si}$ atom.

The $g^{4} \Sigma^{+}$state correlates to the (Rydberg) $\mathrm{Si}\left(3 s^{2} 3 p^{1} 4 s^{1},{ }^{3} P ; M=0\right)+\mathrm{H}\left({ }^{2} S\right)$, and as expected shows a repulsive character up to $r=4.6 \mathrm{bohr}$, Fig. 1 . At this point an avoided crossing is observed with a (not calculated) ${ }^{4} \Sigma^{+}$ state, correlating to $\operatorname{Si}\left(3 s^{2} 3 p^{1} 4 p^{1},{ }^{3} D\right)$ as evidenced from the equilibrium character of the $g^{4} \Sigma^{+}$state, resulting to a minimum at $r_{e}=1.548 \AA$. The leading configurations, with a 
"+" instead of a "- " sign, orbitals, distributions, and bonding are identical to those of the $f^{4} \Delta$ state. Finally, the $g^{4} \Sigma^{+}$ is bound with respect to its adiabatic asymptote by $1.60 \mathrm{kcal} /$ $\mathrm{mol}$, or by $24.7 \mathrm{kcal} / \mathrm{mol}$ with respect to $\mathrm{Si}\left(3 s^{2} 3 p^{1} 4 p^{1},{ }^{3} D\right)+\mathrm{H}\left({ }^{2} S\right)$.

\section{J. $d^{6} \Sigma^{-}$state}

A purely repulsive state correlating to $\mathrm{Si}\left({ }^{5} S\right)+\mathrm{H}\left({ }^{2} S\right)$, Fig. 1. A van der Waals attractive interaction of $9.5 \mathrm{~cm}^{-1}$ is recorded at about 9 bohr.

\section{K. The $\mathrm{SiH}^{+} X^{1} \Sigma^{+}$state}

The fact that an accurate ionization energy (IE) of $\mathrm{SiH}\left(X^{2} \Pi\right)$ has been reported, ${ }^{81}$ motivated us to examine the $\mathrm{SiH}^{+}$ground state. Its potential curve is depicted in Fig. 1. The following parameters are obtained at the MRCI/aug-cc$\mathrm{pV} 6 \mathrm{Z}$ level of theory (experimental results in parentheses): $E=-289.266576$ hartree, $\quad r_{e}=1.5057(1.5041)^{67} \AA, \quad D_{e}$ $=3.43(3.30){ }^{67} \mathrm{eV}$ with respect to $\mathrm{Si}^{+}\left({ }^{2} P ; M=0\right)+H\left({ }^{2} S\right)$, $\omega_{e}\left({ }^{28} \mathrm{SiH}^{+}\right)=2159.3(2157.17)^{67} \mathrm{~cm}^{-1}, \omega_{e} x_{e}=33.72(34.24)^{67}$ $\mathrm{cm}^{-1}$, and $I E=7.92(7.91 \pm 0.01)^{81} \mathrm{eV}$.

\section{SUMMARY}

Employing large valence correlation-consistent basis sets, namely aug-cc-pV6Z/ ${ }_{\mathrm{Si}} \mathrm{cc}-\mathrm{pV} 5 \mathrm{Z} / \mathrm{H}$, and MRCISD techniques, we have constructed a series of 18 potential energy curves of the $\mathrm{SiH}$ radical, plus the PEC of the $X$ state of the $\mathrm{SiH}^{+}$cation.

We report total energies, dissociation energies, bond lengths, dipole moments, and common spectroscopic parameters $\left(\omega_{e}, \omega_{e} x_{e}, \alpha_{e}, \bar{D}_{e}\right)$ for the isotopic species ${ }^{28} \mathrm{Si}-{ }^{1,2} \mathrm{H}$. All our calculated values are in excellent agreement with the rather limited experimental results. In particular, we believe that our estimated $D_{e}\left(X^{2} \Pi\right)$ value of $73.28 \mathrm{kcal} / \mathrm{mol}$ is the most accurate value reported so far in the literature. The $+0.0026 \AA$ discrepancy between calculated and observed bond lengths for the $X$ state could be attributed to corevalence correlation effects. $D_{e}$ and $r_{e} \operatorname{CCSD}(\mathrm{T})$ results for the $X^{2} \Pi$ and $a^{4} \Sigma^{-}$states are identical to those of the MRCI method.

Most of the $\mathrm{SiH}$ states are in close correspondence with the states of the isovalent $\mathrm{CH}$ system, as shown in Table $\mathrm{V}$ and visualized in Fig. 4.

${ }^{1}$ C. V. Jackson, Proc. R. Soc. London, Ser. A 126, 373 (1930).

${ }^{2}$ R. S. Mulliken, Phys. Rev. 37, 733 (1931).

${ }^{3}$ R. W. B. Pearse, Publ. Am. Astron. Soc. 7, 12 (1931).

${ }^{4}$ G. D. Rochester, Z. Phys. 101, 769 (1936).

${ }^{5}$ J. E. Smith, Jr. and T. O. Sedgwick, Thin Solid Films 40, 1 (1977).

${ }^{6}$ B. Drevillon, J. Huc, A. Lloret, J. Perrin, G. deRonsy, and J. P. M. Schmitt, Appl. Phys. Lett. 37, 646 (1980).

${ }^{7}$ M. Taniguchi, M. Hirose, T. Hamasaki, and Y. Osaka, Appl. Phys. Lett. 37, 787 (1980).

${ }^{8}$ A. Matsuda, K. Nakagawa, K. Tanaka, M. Matsumura, S. Yamasaki, H. Okushi, and S. Iizima, J. Non-Cryst. Solids 35/36, 183 (1980).

${ }^{9}$ J. Perrin and E. Delafosse, J. Phys. D 13, 759 (1980).

${ }^{10}$ I. Haller, Appl. Phys. Lett. 37, 282 (1980).

${ }^{11}$ B. Drevillon, J. Huc, A. Lloret, J. Perrin, G. deRonsy, and J. P. M. Schmitt, Appl. Phys. Lett. 37, 282 (1980).

${ }^{12}$ G. Turban, Y. Catherine, and B. Grolleau, Thin Solid Films 67, 309 (1980); 77, 287 (1981).
${ }^{13}$ F. J. Kampas and R. W. Griffith, J. Appl. Phys. 52, 1285 (1981).

${ }^{14}$ J. Perrin and J. P. M. Schmitt, Chem. Phys. 67, 167 (1982).

${ }^{15}$ A. Matsuda and K. Tanaka, Thin Solid Films 92, 171 (1982).

${ }^{16}$ R. Robertson, D. Hils, H. Chatham, and A. Gallagher, Appl. Phys. Lett. 43, 544 (1983).

${ }^{17}$ J. P. M. Schmitt, J. Non-Cryst. Solids 59/60, 649 (1983).

${ }^{18}$ P. Ho and W. G. Breiland, Appl. Phys. Lett. 43, 125 (1983); 44, 51 (1984).

${ }^{19}$ J. P. M. Schmitt, P. Gressier, M. Krishnan, G. de Rosny, and J. Perrin, Chem. Phys. 84, 281 (1984).

${ }^{20}$ Y. Toyoshima, K. Kumada, U. Itoh, K. Arai, A. Matsuda, N. Washida, G. Inoue, and K. Katsuumi, Appl. Phys. Lett. 46, 584 (1985).

${ }^{21}$ N. Washida, Y. Matsumi, T. Hayashi, T. Ibuki, A. Hiraya, and K. Shobatake, J. Chem. Phys. 83, 2769 (1985).

${ }^{22}$ K. Tanaka, A. Matsuda, and N. Hata, Organosilicon and Bioorganosilicon Chemistry (Ellis Horwood, Chichester, 1985), Chap. 24.

${ }^{23}$ P. A. Longeway, H. A. Weakliem, and R. D. Estes, J. Appl. Phys. 57, 5499 (1985).

${ }^{24}$ Y. Matsumi, T. Hayashi, H. Yoshikawa, and S. Komiya, J. Vac. Sci. Technol. A 4, 1786 (1986).

${ }^{25}$ W. G. Tong and R. W. Shaw, Appl. Spectrosc. 40, 494 (1986).

${ }^{26}$ P. Chollet, G. Guelachvili, M. Morillon-Chapey, P. Gressier, and J. P. M. Schmitt, J. Opt. Soc. Am. B 3, 687 (1986).

${ }^{27}$ A. Loret and L. Abouaf-Marguin, Chem. Phys. 107, 139 (1986).

${ }^{28}$ M. Nemoto, A. Suzuki, H. Nakamura, K. Shibuya, and K. Obi, Chem. Phys. Lett. 162, 467 (1989).

${ }^{29}$ M. H. Begemann, R. W. Dreyfus, and J. M. Jasinski, Chem. Phys. Lett. 155, 351 (1989).

${ }^{30}$ P. Ho, W. G. Breiland, and R. J. Buss, J. Chem. Phys. 91, 2627 (1989).

${ }^{31}$ J. M. Jasinski and S. M. Gates, Acc. Chem. Res. 24, 9 (1991).

${ }^{32}$ S. Tsurubuchi, K. Motohashi, S. Matsuoka, and T. Arikawa, Chem. Phys. 161, 493 (1992).

${ }^{33}$ J. M. Jasinski, R. Becerra, and R. Walsh, Chem. Rev. 95, 1203 (1995).

${ }^{34}$ U. K. Das and P. Chaudhuri, Chem. Phys. Lett. 298, 211 (1998).

${ }^{35}$ D. N. Davis, Publ. Astron. Soc. Pac. 52, 280 (1940).

${ }^{36}$ H. D. Babcock, Astrophys. J. 102, 154 (1945).

${ }^{37}$ A. Schadee, Bull. Astron. Inst. Neth. 17, 311 (1964).

${ }^{38}$ A. E. Douglas and G. A. Elliot, Can. J. Phys. 43, 496 (1965).

${ }^{39}$ C. E. Moore-Sitterly, in Proceedings of the Meeting on Sunspots (Firenze, Italy, 1964), Vol. 2, p. 181 (1966).

${ }^{40}$ C. E. Moore, M. G. J. Minnaert, and J. Houtgast, National Bureau of Standards, Monograph 61, Washington, D.C. (1966).

${ }^{41}$ A. Schadee, J. Quant. Spectrosc. Radiat. Transf. 7, 169 (1967).

${ }^{42}$ H. J. Habing, Bull. Astron. Inst. Neth. 19, 421 (1968).

${ }^{43}$ A. J. Sauval, Sol. Phys. 10, 319 (1969).

${ }^{44}$ A. E. Douglas and B. L. Lutz, Can. J. Phys. 48, 247 (1970).

${ }^{45}$ D. L. Lambert and E. A. Malia, Mon. Not. R. Astron. Soc. 148, 313 (1970).

${ }^{46}$ N. Grevesse and A. J. Sauval, Astron. Astrophys. 9, 232 (1970).

${ }^{47}$ N. Grevesse and A. J. Sauval, J. Quant. Spectrosc. Radiat. Transf. 11, 65 (1971).

${ }^{48}$ T. D. Fay, Jr., W. L. Stein, and W. H. Warren, Jr., Publ. Astron. Soc. Pac. 86, 772 (1974).

${ }^{49}$ J. L. Turner and A. Dalgarno, Astrophys. J. 213, 386 (1977).

${ }^{50}$ R. A. Bell and M. J. Tripicco, Astron. J. 102, 777 (1991).

${ }^{51}$ C. Jascheck and M. Jascheck, The Behavior of Chemical Elements in Stars (Cambridge University Press, Cambridge, U.K., 1995).

${ }^{52}$ A. E. Douglas, Can. J. Phys. 35, 71 (1957).

${ }^{53}$ B. A. Thrush, Nature (London) 186, 1044 (1960).

${ }^{54}$ P. G. Wilkinson, Astrophys. J. 138, 778 (1963).

${ }^{55}$ R. D. Verma, Can. J. Phys. 43, 2136 (1965).

${ }^{56}$ L. Klynning and B. Lindgren, Ark. Fys. 33, 73 (1966).

${ }^{57}$ M. S. Vardya, Mon. Not. R. Astron. Soc. 134, 877 (1966).

${ }^{58}$ S. Morris and A. A. Wyller, Astrophys. J. 150, 877 (1967).

${ }^{59}$ A. G. Gaydon, Dissociation Energies and Spectra of Diatomic Molecules (Chapman and Hall, London, 1968).

${ }^{60}$ G. Herzberg, A. Lagerqvist, and B. J. McKenzie, Can. J. Phys. 47, 1889 (1969).

${ }^{61}$ W. H. Smith, J. Chem. Phys. 51, 520 (1969).

${ }^{62}$ P. Bollmark, L. Klynning, and P. Pagès, Phys. Scr. 3, 219 (1971).

${ }^{63}$ R. S. Freedman and A. W. Irwin, Astron. Astrophys. 53, 447 (1976).

${ }^{64}$ T. A. Carlson, N. Đurić, P. Erman, and M. Larsson, J. Phys. B 11, 3667 (1978).

${ }^{65}$ L. Klynning, B. Lindgren, and U. Sassenberg, Phys. Scr. 20, 617 (1979).

${ }^{66}$ C. Park, J. Quant. Spectrosc. Radiat. Transf. 21, 373 (1979). 
${ }^{67}$ K. P. Huber and G. Herzberg, Constants of Diatomic Molecules (Van Nostrand Reinhold, New York, 1979).

${ }^{68}$ R. Walsh, Acc. Chem. Res. 14, 246 (1981).

${ }^{69}$ J. C. Knights, J. P. M. Schmitt, J. Perrin, and G. Guelachvili, J. Chem. Phys. 76, 3414 (1982).

${ }^{70}$ P. Chollet, G. Guelachvili, and M. Morillon-Chapey, Bull. Soc. Chim. Belg. 92, 152 (1983).

${ }^{71}$ J. Perrin and J. F. M. Aarts, Chem. Phys. 80, 351 (1983).

${ }^{72}$ J. M. Brown and D. Robinson, Mol. Phys. 51, 883 (1984).

${ }^{73}$ J. M. Brown, R. F. Curl, and K. M. Evenson, J. Chem. Phys. 81, 2884 (1984).

${ }^{74}$ W. Bauer, K. H. Becker, R. Düren, C. Hubrich, and R. Meuser, Chem. Phys. Lett. 108, 560 (1984).

${ }^{75}$ P. B. Davies, N. A. Isaacs, S. A. Johnson, and D. K. Russell, J. Chem. Phys. 83, 2060 (1985).

${ }^{76}$ J. M. Brown, R. F. Curl, and K. M. Evenson, Astrophys. J. 292, 188 (1985).

${ }^{77}$ J. M. Jasinski, J. Phys. Chem. 90, 555 (1986).

${ }^{78}$ M. Betrencourt, D. Boudjaadar, P. Chollet, G. Guelachvili, and M. Morillon-Chapey, J. Chem. Phys. 84, 4121 (1986).

${ }^{79}$ W. Seebass, J. Werner, W. Urban, E. R. Comben, and J. M. Brown, Mol. Phys. 62, 161 (1987).

${ }^{80}$ B. H. Boo and P. B. Armentrout, J. Am. Chem. Soc. 109, 3549 (1987).

${ }^{81}$ J. Berkowitz, J. P. Greene, H. Cho, and B. Rušcić, J. Chem. Phys. 86, 1235 (1987)

${ }^{82}$ R. D. Johnson, III and J. W. Hudgens, J. Phys. Chem. 93, 6268 (1989).

${ }^{83}$ B. H. Boo, J. L. Elkind, and P. B. Armentrout, J. Am. Chem. Soc. 112, 2083 (1990).

${ }^{84}$ R. S. Ram, R. Englemen, Jr., and P. F. Bernath, J. Mol. Spectrosc. 190, 341 (1998).

${ }^{85}$ R. S. Mulliken, Rev. Mod. Phys. 4, 1 (1932).

${ }^{86}$ P. C. Jordan, J. Chem. Phys. 44, 3400 (1966).

${ }^{87}$ P. E. Cade and W. M. Huo, J. Chem. Phys. 47, 649 (1967).

${ }^{88}$ P. E. Cade, Proc. Phys. Soc. 91, 842 (1967).

${ }^{89}$ P. E. Cade, R. F. W. Bader, W. H. Henneker, and I. Keaveny, J. Chem. Phys. 50, 5313 (1969).

${ }^{90}$ B. Wirsam, Chem. Phys. Lett. 10, 180 (1971).

${ }^{91}$ T. V. Ramakrishna Rao and S. V. J. Lakshman, Physica 56, 322 (1971).

${ }^{92}$ W. H. Smith and H. S. Liszt, J. Quant. Spectrosc. Radiat. Transf. 11, 45 (1971).

${ }^{93}$ L. Veseth, Physica 56, 286 (1971).

${ }^{94}$ A. Dalgarno and R. A. McCray, Annu. Rev. Astron. Astrophys. 10, 375 (1972).

${ }^{95}$ J. Higuchi, S. Kubota, T. Kumamoto, and I. Tokue, Bull. Chem. Soc. Jpn. 47, 2775 (1974)

${ }^{96}$ W. Meyer and P. Rosmus, J. Chem. Phys. 63, 2356 (1975).

${ }^{97}$ I. D. L. Wilson and W. G. Richards, Nature (London) 258, 133 (1975),

${ }^{98}$ P. Rosmus and W. Meyer, J. Chem. Phys. 66, 13 (1977).

${ }^{99}$ M. S. Gordon, Chem. Phys. Lett. 59, 410 (1978).

${ }^{100}$ P. D. Singh and F. G. Vanlandingham, Astron. Astrophys. 66, 87 (1978).

${ }^{101}$ W. A. Goddard, III and L. B. Harding, Annu. Rev. Phys. Chem. 29, 363 (1978).

${ }^{102}$ H. P. Trivedi and W. G. Richards, J. Chem. Phys. 72, 3438 (1980).

${ }^{103}$ D. L. Cooper and W. G. Richards, J. Chem. Phys. 74, 96 (1981).

${ }^{104}$ A. Mavridis and J. F. Harrison, J. Phys. Chem. 86, 1979 (1982).

${ }^{105}$ (a) M. Lewerenz, P. J. Bruna, S. D. Peyerimhoff, and R. J. Buenker, Mol. Phys. 49, 1 (1983); (b) J. Phys. B 16, 4511 (1983).

${ }^{106}$ D. Power, P. Brint, and T. Spalding, J. Mol. Struct.: THEOCHEM 108, 81 (1984).
${ }^{107}$ J. A. Pople, B. T. Luke, M. J. Frisch, and J. S. Binkley, J. Phys. Chem. 89, 2198 (1985).

${ }^{108}$ P. Ho, M. E. Coltrin, J. S. Binkley, and C. F. Melius, J. Phys. Chem. 89, 4647 (1985).

${ }^{109}$ S. Oikawa, M. Tsuda, J. Yoshida, and Y. Jisai, J. Chem. Phys. 85, 2808 (1986).

${ }^{110}$ L. G. M. Pettersson and S. R. Langhoff, Chem. Phys. Lett. 125, 429 (1986).

${ }^{111}$ W. D. Allen and H. S. Schaefer, III, Chem. Phys. 108, 243 (1986).

${ }^{112}$ (a) A. Amore-Bonapasta, C. Battistoni, A. Lapiccirella, E. Semprini, F. Stefani, and N. Tomassini, Nuovo Cimento 6D, 51 (1985); (b) 9D, 156 (1987).

${ }^{113}$ M. Larsson, J. Chem. Phys. 86, 5018 (1987).

${ }^{114}$ J. Kalcher, Chem. Phys. 118, 273 (1987).

${ }^{115}$ J. A. Pople and L. A. Curtiss, J. Phys. Chem. 91, 155 (1987).

${ }^{116}$ D. S. Horowitz and W. A. Goddard, III, J. Mol. Struct.: THEOCHEM 163, 207 (1988).

${ }^{117}$ L. A. Curtiss and J. A. Pople, Chem. Phys. Lett. 144, 38 (1988).

${ }^{118}$ P. Ho and C. F. Melius, J. Phys. Chem. 94, 5120 (1990).

${ }^{119}$ K. K. Baeck and Y. S. Lee, J. Chem. Phys. 93, 5775 (1990).

${ }^{120}$ A. F. Sax and J. Kalcher, J. Phys. Chem. 95, 1768 (1991).

${ }^{121}$ G. Leroy, M. Sana, C. Wilante, and D. R. Temsamani, J. Mol. Struct.: THEOCHEM 259, 369 (1992).

${ }^{122}$ J. K. Park and H. Sun, Chem. Phys. Lett. 195, 469 (1992).

${ }^{123}$ R. S. Grev and H. F. Schaefer, III, J. Chem. Phys. 97, 8389 (1992).

${ }^{124}$ H. H. Michels and R. H. Hobbs, Chem. Phys. Lett. 207, 389 (1993).

${ }^{125}$ (a)C. Winter and P. Millié, Chem. Phys. 174, 177 (1993); (b)174, 191 (1993).

${ }^{126}$ D. E. Woon and T. H. Dunning, Jr., J. Chem. Phys. 99, 1914 (1993).

${ }^{127}$ J. Kalcher and A. F. Sax, J. Mol. Struct.: THEOCHEM 313, 41 (1994).

${ }^{128}$ J. Paldus and X. Li, Can. J. Chem. 74, 918 (1996).

${ }^{129}$ C. W. Greeff and W. A. Lester, Jr., J. Chem. Phys. 106, 6412 (1997)

${ }^{130}$ D. Feller and D. A. Dixon, J. Phys. Chem. A 103, 6413 (1999).

${ }^{131}$ D. Ajitha and S. Pal, Chem. Phys. Lett. 309, 457 (1999).

${ }^{132}$ (a) T. H. Dunning, Jr., J. Chem. Phys. 90, 1007 (1989); (b) Basis sets were obtained from the Extensible Computational Chemistry Environment Basis Set Database, Version 10/12/01, as developed and distributed by the Molecular Science Computing Facility, Environmental and Molecular Sciences Laboratory which is part of the Pacific Northwest Laboratory, P.O. Box 999, Richland, Washington 99352, and funded by the U.S. Department of Energy. The Pacific Northwest Laboratory is a multiprogram laboratory operated by Battelle Memorial Institute for the U.S. Department of Energy under Contract DE-AC06-76RLO 1830. Contact David Feller or Karen Schuchardt for further information.

${ }^{133}$ MOLPRO is a package of ab initio programs written by H.-J. Werner and P. J. Knowles, with contributions from R. D. Amos, A. Bernhardsson, A. Berning et al. (2001).

${ }^{134}$ (a) K. Docken and J. Hinze, J. Chem. Phys. 57, 4928 (1972); (b) H.-J. Werner and W. Meyer, ibid. 74, 5794 (1981).

${ }^{135}$ S. F. Boys and F. Bernardi, Mol. Phys. 19, 553 (1970).

${ }^{136}$ ROVIB program developed in this laboratory (2001).

${ }^{137}$ C. E. Moore, Atomic Energy Levels, NSRDS-NBS Circular 3 (U.S. Government Printing Office, Washington, DC, 1971).

${ }^{138}$ C. F. Bunge, J. A. Barientos, A. V. Bunge, and J. A. Gogordan, Phys. Rev. A 46, 3691 (1992).

${ }^{139}$ A. Kalemos, A. Mavridis, and A. Metropoulos, J. Chem. Phys. 111, 9536 (1999).

${ }^{140}$ NIST Atomic Spectra DataBase (http://physics.nist.gov/cgi-bin/AtData/ main_asd) 